ISSN: 0213-2060

DOI: https://doi.org/10.14201/shhme2019372155178

\title{
LA RESTAURACIÓN DE LA DIÓCESIS DE ÁVILA Y EL EPISCOPADO DE LA REPOBLACIÓN (1085-1198) ${ }^{1}$
}

\section{The Restoration of the Diocese of Avila and the Episcopate of the Repopulation (1085-1198)}

\author{
José Antonio CALVO GÓMEZ \\ Instituto Español de Historia Eclesiástica. ROMA - Depto. de Humanidades. Facultad de Ciencias Sociales \\ y Jurídicas. Universidad Católica de Ávila. C/ Canteros, s/n. E-05005 ÁVILA. C. e.: jantonio.calvo@ucavila.es
}

Recibido: 2019-07-23

Revisado: 2019-10-01

Aceptado: 2019-11-08

RESUMEN: Este trabajo trata de interpretar cómo se pudo alcanzar la restauración de la estructura diocesana en Ávila, durante los siglos XI y XII, en un proceso más amplio de repoblación de los Extrema Durii castellanos. Frente al modelo propuesto por Sánchez-Albornoz, la historiografía contemporánea ya no contempla la hipótesis sobre la despoblación total de los valles y las serranías centrales durante los siglos IX y x. Pero hoy tampoco hay duda de que en este territorio, durante la Alta Edad Media, la estructura de poder institucional de la Iglesia quedó desmantelada. La obra de Alfonso VI y Raimundo de Borgońa parece estar detrás de la reinstalación de los titulares de la mitra en la ciudad de Ávila.

Palabras clave: Episcopado; Repoblación; Ávila; Alfonso VI; Raimundo de Borgoña.

ABSTRACT: This work tries to offer an interpretation to understand how the restoration of the diocesan structure in Ávila, during the $11^{\text {th }}$ and $12^{\text {th }}$ Centuries, could be achieved in a broader process of repopulation of the Castilian Extrema Durii. In opposition to the model proposed by Sánchez-Albornoz, contemporary historiography no longer contemplates the hypothesis about the total depopulation of the central valleys and mountains during the $9^{\text {th }}$ and $10^{\text {th }}$ Centuries. But today there is no doubt that, in this territory, during

1 Este trabajo ha sido realizado en el marco del proyecto de investigación «El clero secular en la Edad Media. El episcopado abulense de la repoblación bajomedieval (1085-1198) según la documentación del Archivo Secreto Vaticano", con la ayuda del Centro Español de Estudios Eclesiásticos anejo a la Iglesia Nacional Espańola de Santiago y Montserrat en Roma en el marco de los proyectos de investigación del curso 2016-2017.

Siglas y abreviaturas: AC: Archivo de la Catedral de Ávila; AHN: Archivo Histórico Nacional; ASV: Archivio Segreto Vaticano; BN: Biblioteca Nacional de Madrid. 
LA RESTAURACIÓN DE LA DIÓCESIS DE ÁVILA Y EL EPISCOPADO DE LA REPOBLACIÓN (1085-1198) 156 JOSÉ ANTONIO CALVO GÓMEZ

the High Middle Ages, the institutional power structure of the Church was dismantled. The work of Alfonso VI and Raimundo de Borgoña seems to be behind the reinstatement of the headlines of the miter in the city of Ávila.

Keywords: Episcopate; Repopulation; Ávila; Alfonso VI; Raimundo de Borgońa.

SUMARIO: 0 Introducción. 1 Las principales referencias diplomáticas e historiográficas. 2 El itinerario para la restauración de la iglesia abulense. Jerónimo de Perigord, administrador desde 1103 a 1120. 3 Los siete sucesores de don Jerónimo, en Ávila, durante el siglo XII. 4 Conclusión. 5 Referencias bibliográficas.

\section{INTRODUCCIÓN}

Un breve pasaje historiográfico, publicado a mediados del siglo XviıI por el padre Enrique Flórez, a pesar de su evidente lirismo y las dificultades para probar algunas de sus afirmaciones según los criterios actuales, menciona dos teorías sobre la dinámica de la repoblación de los Extrema Durii castellanos que, según los análisis contemporáneos que hemos tenido ocasión de conocer, no estarían tan alejadas de la realidad. Dice el historiador:

En la dominación de los moros, padeció Ábila las aflicciones que otras, y acaso más, si fue más firme su resistencia, por lo que acaso refieren algunos antiguos monumentos, que los sarracenos la destruyeron, lo que debe entenderse de daños y menoscabos, no de asolación pues el Chronicon de Sebastián [...] refiere la traslación de las reliquias de san Vicente y sus hermanas desde Ávila a León y esto supone en pie la iglesia de los mártyres. Del rey don Alfonso VI, dice que la pobló a Salamanca y Ávila, no que las levantó, pues existían; pero, como las continuas guerras tenían extenuadas las murallas, y eran pocos los christianos que se mantenían en algunos pueblos dominados de moros, no podían los reyes conservar mucho tiempo las conquistas [...]. Por tanto, no debemos suponer a Ábila sin muzárabes; pero, si tenían obispo, no ha quedado memoria segura que yo conozca hasta el tiempo de la repoblación, en el reynado de don Alfonso VI, el que tomó Toledo².

La primera hipótesis, contra los estudios de Claudio Sánchez-Albornoz ${ }^{3}$, plantea la existencia, en el territorio abulense, de ciertas poblaciones cristianas, más o menos

2 Flórez, Enrique. España Sagrada. Theatro geográphico histórico de la Iglesia de España. Origen, divisiones y limites de todas sus provincias, antigüedad y traslaciones, y estado antiguo y presente de sus sillas, con varias disertaciones críticas. Tomo XIV. De las Iglesias de Ábila, Caliabria, Coria, Coimbra, Ébora, Egitania, Lamego, Lisboa, Osonoba, Pacense, Salamanca, Viseo y Zamora, según su estado antiguo. Madrid: Imprenta de Pedro Martín, 1786, pp. 27-28.

3 SÁnchez-Albornoz, Claudio. España, un enigma histórico. Buenos Aires: Editorial Sudamericana, 1956; ÍD. Despoblación y repoblación del valle del Duero. Buenos Aires: Instituto de Historia de España, 1966. En el mismo sentido, vid. Menéndez Pidal, Ramón. «Repoblación y tradición en la cuenca del Duero». En Enciclopedia lingüistica hispánica. Madrid: Consejo Superior de Investigaciones Científicas, 1960, vol. I, pp. 29-57; ÍD. La España del Cid. 7. a ed. Madrid: Espasa-Calpe, 1967. Años después, como sucesora de su maestro, Pastor, Reyna. «Claudio Sánchez-Albornoz, historiador, maestro y militante». En PASTOR, Reyna (dir.). Sánchez-Albornoz a debate. Homenaje en la Universidad de Valladolid con motivo de su centenario. Valladolid: Universidad de Valladolid, 1993, pp. 33-44. 
arabizadas, sin duda residuales, que, entre otras actuaciones, sostendrían la noticia del martirio de los santos hermanos Vicente, Sabina y Cristeta, así como la presencia de sus cuerpos en cierto templo más o menos arruinado. Los estudios toponímicos, las investigaciones arqueológicas en relación con las tumbas excavadas en roca a lo largo del Sistema Central, los análisis de los despoblados de la cabecera del Tormes, así como nuestras propias investigaciones sobre el origen del antiguo monasterio de Santa María del Burgo, en el Alto Alberche, no han hecho más que revalidar, con distintas y complementarias comprobaciones, esta aparentemente gratuita afirmación del historiador agustino ${ }^{4}$.

La segunda hipótesis parece más sencilla de probar. Desde principios del siglo vIII hasta finales del XI, la estructura eclesial en este territorio habría sido desmantelada y, durante unos cuatrocientos años, la diócesis de Ávila no habría contado con ningún titular en la sede de san Segundo. En la práctica, aunque la presencia de ciertas poblaciones cristianas llegara a confirmarse arqueológicamente para los siglos IX y x, que podríamos llamar «los siglos oscuros de la Iglesia abulense», la actividad de la jerarquía eclesial habría desaparecido. No se podría hablar de construcción de ningún templo ni de la actividad de sus prelados durante el periodo carolingio y, solo con dificultades, podríamos empezar a plantear ciertas hipótesis para el reinado de Alfonso VI, que murió en Toledo el 1 de julio de 1109 .

En este trabajo, pretendemos llegar a cierta conclusión sobre la restauración de la diócesis de Ávila; interpretar los acontecimientos que vivió esta Iglesia local durante la Reforma Gregoriana; y delimitar el protagonismo que cobró el episcopado durante la repoblación de este territorio de la Extremadura castellana. La primera actuación de los reformadores, ya con León IX (1049-1054), tuvo como objetivo la recuperación del

4 Barrios García, Ángel. «Repoblación de la zona meridional del Duero. Fases de ocupación, procedencias y distribución espacial de los grupos repobladores». Studia Historica. Historia Medieval, 1985 , vol. 3, pp. 33-82; ÍD. «Romanización y reconquista en la Península Ibérica: nuevas perspectivas». Cassiodorus, 1997, vol. 3 pp. 147-152; ÍD. «Conquista y repoblación: el proceso de reconstrucción del poblamiento y el aumento demográfico», y «Repoblación y colonización: la dinámica de creación de paisajes y el crecimiento económico». En Barrios García, Ángel (coord.). Historia de Ávila. Vol. II, Edad Media (siglos VIII-XIII). Ávila: Institución Gran Duque de Alba, 2000, pp. 227-270 y 271-336; Calvo GómEz, José Antonio. El monasterio de Santa María de Burgohondo en la Edad Media. Ávila: Institución Gran Duque de Alba, 2009; Casa MartíNEz, Carlos de la. «Despoblación y repoblación de los Extrema Durii». En: Repoblación y reconquista. Actas del III Curso de cultura medieval. Aguilar de Campoo: Centro de Estudios del Románico, 1993, pp. 89-94; Estepa Díez, Carlos. El reinado de Alfonso VI. Madrid: Spainfo, 1985; Gamba, Andrés. Alfonso VI. Cancillería, curia e imperio. León: Centro de Estudios e Investigación San Isidoro, 1997-1998, 2 vols.; González, Julio. «La repoblación de la Extremadura leonesa». Hispania, 1943, vol. 11, pp. 195-273; ÍD. «La Extremadura castellana al mediar el siglo xiII». Hispania, 1974, vol. 127, pp. 265-424; Moxó Ortiz de Villajos, Salvador de. Repoblación y sociedad en la España cristiana medieval. Madrid: Rialp, 1979; Martín Viso, Iñaki. "Capere vel populare. Formación y desarrollo de una frontera feudal entre el Duero y el Tajo (siglos XI-XIII)». En $B a-$ laguer 1105. Cruilla de civilitzacions. Lleida: Pagès Editors, 2007, pp. 177-223; Mínguez Fernández, José María. Alfonso VI: poder, expansión y reorganización interior. Hondarribia: Nerea, 2000; Mínguez FernánDeZ, José María y Ser Quijano, Gregorio del (coords.). La Peninsula en la Edad Media: treinta años después. Estudios dedicados a José-Luis Martín. Salamanca: Universidad de Salamanca, 2006; Rodríguez Morales, Jesús y González Agudo, David. «Los caminos de la repoblación segoviana en la Transierra entre los siglos XIII y xv. El privilegio de las Alberguerías de 1273». Espacio, Tiempo y Forma. Serie III, Historia Medieval, 2019, vol. 23, pp. 303-336. 
LA RESTAURACIÓN DE LA DIÓCESIS DE ÁVILA Y EL EPISCOPADO DE LA REPOBLACIÓN (1085-1198) 158

JOSÉ ANTONIO CALVO GÓMEZ

solar hispánico para la causa cristiana. En concreto, sobre el territorio abulense podemos hablar, sobre todo, de lo que vivió la Iglesia desde la muerte de Gregorio VII (10731085), uno de sus principales promotores, el 25 de mayo de 1085. Ese día se dató, también, la solemne entrada de Alfonso VI en la antigua capital del reino visigodo de Toledo. Creemos que resulta ser un tema zanjado entender que, hasta ese momento, no se dieron los primeros pasos para la rehabilitación de la desmantelada jurisdicción de la mitra abulense ${ }^{5}$.

Hemos denominado «el episcopado de la repoblación» al que, desde 1085, rigió los destinos de la Iglesia en este territorio hasta la elección del papa Inocencio III en 1198. El ministerio pontificio de Lotario de Segni (1198-1216) representó un conjunto de novedades tan importantes en el gobierno institucional que su interpretación nos llevaría más allá de nuestros intereses. Después de 1198, se constata una circunstancia no menor para esta investigación. La formación como jurista de Inocencio III se dejó notar en la actividad de la Curia romana. El papa exigió a sus oficiales un seguimiento directo del devenir de las diócesis, lo que, de hecho, permitiría reconstruir, con mejores instrumentos diplomáticos, cuanto tuvo lugar en esta sede. Queremos centrarnos en estos primeros algo más de cien años de la repoblación del Pleno Medievo abulense (1085-1198), más difíciles de ordenar e interpretar, pero, a la vez, más interesantes desde el punto de vista del estudio de la conformación de una jurisdicción espiritual en la avanzadilla de la colonización castellana más allá de la frontera natural que representa, en un sentido, el río Duero y, sobre todo, el Sistema Central que se contempla desde este altozano rocoso, en la submeseta norte.

\section{LAS PRINCIPALES REFERENCIAS DIPLOMÁTICAS E HISTORIOGRÁFICAS}

Para tratar de explicar cómo se produjo la restauración de la diócesis de Ávila a finales del siglo xi y qué actuación puede adjudicarse a los obispos de la etapa de la repoblación castellana durante el siglo XII, se pueden citar algunos textos historiográficos

5 Vid. Calvo Gómez, José Antonio. «Rasgos de la reforma del clero en la Península Ibérica durante el siglo XI». Studia Historica. Historia Medieval, 2015, vol. 33, pp. 201-232. Allí recogimos el manifiesto gregoriano Ad principes Hispaniae de 30 de abril de 1073, en que Gregorio VIII explicaba que el reino de España perteneció antiguamente de derecho a San Pedro y que, en esos momentos, aunque todavía estuviese ocupado por paganos, ese derecho seguía siendo imprescriptible: «Non latere vos credimus regnum Hispaniae ad antiquo propii juris Sancti Petri fuisse, et adhuc (licet diu a paganis sit occupatam) lege tamen justitiae non evacuata, nulli mortalium, sed soli Apostolicae Sedi ex aequo pertinere... Itaque comes Evulus de Roceio... terram illam ad honorem Sancti Petri ingredi et paganorum manibus eripere cupiens, hanc concessionem ab Apostolica Sede obtinuit ut partem illam unde paganos suo studio et adjuncto sibi aliorum auxilio expellere posset, sub conditione inter nos factae pactionis ex parte Sancti Petri possideret». Epístola VII, Patrología Latina, París, 1884-1856, vol. 148, col. 289-290. Vid. Magaz Fernández, José María y Álvarez de las Asturias, Nicolás (eds.). Reforma Gregoriana en España. Madrid: Universidad San Dámaso, 2011. Sobre la Reforma Gregoriana, vid. también: CANTARELLA, Glauco Maria. Il sole e la luna. La rivoluzione di Gregorio VII, papa 1073-1085. Roma-Bari: Laterza, 2005; Deswarte, Tomas. Une Chrétienté romaine sans pape: l'Espagne et Rome (586-1085). Paris: Garnier, 2010. Sobre la restauración de las diócesis en Europa, vid. MAZEL, Florian. "Cuius dominus, eius episcopatus? Pouvoir seigneurial et territoire diocésain ( $\mathrm{x}^{\mathrm{e}}$-XIII ${ }^{\mathrm{e}}$ siècle)». En Mazel, Florian (ed.). L'espace du diocèse. Genèse d'un territoire dans l'Occident médiéval (V'-XII' siècle). Rennes: Presses Universitaires de Rennes, 2008, pp. 213-252. 
de los siglos XIII al XVII, cuyo rigor científico debería ser analizado despacio. Hace dos ańos veía la luz un texto de José María Monsalvo, de la Universidad de Salamanca, en el que, junto al estudio sobre la Crónica de la Población de Ávila, datada en torno al 1256, y a la llamada Segunda Leyenda, de finales del siglo XvI, hacía un repaso de algunos de estos cronicones de la Modernidad ${ }^{6}$. Entre otros, citaba las obras de Gonzalo de Ayora y Luis Ariz. ${ }^{8}$ A ellos habría que añadir los textos de Antonio de Cianca ${ }^{9}$, Gil González Dávila ${ }^{10}$ y Bartolomé Fernández Valencia ${ }^{11}$, el episcopologio de José Tello Martínez ${ }^{12}$ y la

6 Monsalvo Antón, José María. «El imaginario de la repoblación de Ávila: la Crónica de la Población, el Epílogo y la Segunda Leyenda». Anuario de Estudios Medievales, 2017, vol. 47, n. o 1, pp. 177-210.

7 AyOrA, Gonzalo de. Epílogo de algunas cosas dignas de memoria pertenecientes a la yllustre e muy magnifica e muy leal ciudad de Ávila. Salamanca: Lorenzo de Liom de Dei, 1519 (Madrid: Antonio del Riego, 1851).

8 Ariz, Luys. Historia de las grandezas de la ciudad de Ávila. Alcalá de Henares: Luys Martínez Grande, 1607.

9 Cianca, Antonio de. Historia de la vida, invención, milagros y translación de S. Segundo, primero Obispo de Auila: y recopilación de los Obispos sucessores suyos, hasta D. Geronimo Manrique de Lara, inquisidor general de España. Madrid: por Luis Sánchez, 1595. En los folios 75v-81r se refiere a una serie de prelados que, fiado de las listas del padre Gerónimo Román, enumera sin comprobar: 1080, Domingo; 1105, Pedro; 1133, Juan; 1142, Íńigo; 1181, Sancho; 1182, Domingo II; 1187, Iago o Diego; 1190, Domingo III; 1196, Diego II.

10 González Dávila, Gil. Teatro eclesiástico de la S. Iglesia Apostólica de Ávila y vidas de sus hombres ilustres. Madrid: en la imprenta de Pedro de Horna y Villanueva, 1647, pp. 236-247. Este autor sitúa a Pedro Sánchez Zurraquines como primer prelado tras la restauración de la diócesis, que habría levantado la catedral en tiempo de Raimundo de Borgońa. La leyenda de Zurraquines como constructor de la catedral hoy no se sostiene, a pesar de que fue aceptada sin fisuras por Martín Carramolino, Juan. Historia de Ávila, su provincia y obispado. Ávila: Librería Española, 1872, tomo II, p. 235, quien, como González Dávila, omite la figura, incuestionable por la historiografía contemporánea, del obispo Jerónimo de Perigord. En la actualidad, la posible elección de Zurraquines para sustituir a don Jerónimo ha sido recuperada por MARTínez, Gonzalo. «Restauración y límites de la diócesis palentina». Publicaciones de la Institución Tello Téllez de Meneses, 1988, vol. 59, pp. 351-386. La Historia Compostelana. España Sagrada, tomo XX. Madrid: Imprenta de Pedro Martín, 1765, p. 308, menciona la elección de este prelado para sustituir a Jerónimo de Perigord. Añade que fue convocado al concilio provincial compostelano del 9 de enero de 1121. Sin embargo, en el mismo año menciona a Sancho, electo de Ávila, convocado a Compostela por el cardenal legado Bosso para ser consagrado y jurar obediencia al arzobispo Gelmírez sin que se vuelva a tener noticia del supuesto episcopado abulense de Pedro Sánchez Zurraquines. Vid. Historia Compostelana, pp. 322-323. Esta misma obra, al referir los suscriptores del concilio de Oviedo de 1115, menciona a Sanctius, episcopus abulensis, junto a los prelados Bernardo de Sigüenza, Nunio de Salamanca y Bernardo de Salamanca, que iniciaron su ministerio en 1121, 1124 y 1121, respectivamente. Por tanto, no soporta el menor examen historiográfico. Vid. Martínez, «Restauración y límites de la diócesis palentina», p. 366. La relación que presenta González Dávila al supuesto episcopado de Sánchez Zurraquines, no exenta de ciertas incoherencias cronológicas, sería la que sigue: 1130 , Suero; 1133, Juan; 1133-1153, Íńigo; 1149-1153, Pedro II; 1158, Diego de Lugo; 1181, Sancho; 1182, Domingo Blasco; 1182-1187, Diego II; 1187-1190, Domingo II; 1190-1196, Diego III.

11 Fernández Valencia, Bartolomé. Historia y grandezas del insigne templo... de los santos mártires hermanos San Vicente, Santa Sabina y Santa Cristeta... con un comentario o epílogo de las grandezas de esta ciudad, 1676, ed. de Tomás Sobrino Chomón. Ávila: Institución Gran Duque de Alba, 1992.

12 Tello Martínez, José. Cathálogo sagrado de los obispos de Ávila (1788), ed. de Félix A. Ferrer García. Ávila: Institución Gran Duque de Alba, 2001. Su episcopologio bajomedieval se inicia con el ministerio de don Jerónimo, hacia 1103; al que seguiría, en la tradición de Gil González Dávila, el obispo Pedro Sánchez Zurraquines, hacia 1120. Luego añade, con dudas, a Sancho I. Reconoce que le llama la atención la posible suscripción del abulense del sínodo de Oviedo de 1115, que cree un falso histórico. Luego, continúa la relación: 1130, Severo; 1133, Juan; 1142, Íńigo; 1149, Pedro II; 1150, Sancho II; 1159, Diego de Lugo; 1168-1181, Sancho III; 1182, Domingo II; 1187, Diego; 1187-1190, Domingo III; 1196, Diego III. 
LA RESTAURACIÓN DE LA DIÓCESIS DE ÁVILA Y EL EPISCOPADO DE LA REPOBLACIÓN (1085-1198) JOSÉ ANTONIO CALVO GÓMEZ

160

monografía, en tres volúmenes, de Juan Martín Carramolino ${ }^{13}$, sobre todo el segundo. Estas obras, en algunos casos, han sido editadas en nuestros días después de que sus manuscritos reposaran, durante siglos, en diferentes archivos históricos.

Las explicaciones sobre la restauración de la Iglesia y la repoblación abulense han encontrado eco en otros historiadores contemporáneos que, en un intento de adecuación a la ciencia historiográfica más rigurosa, han acudido a nuevas fuentes documentales. Además del citado profesor Monsalvo, cabe mencionar los trabajos de Ińaki Martín Viso y de los desaparecidos Carmelo Luis y Ángel Barrios, que editó los Documentos de la Catedral de Ávila en 1981 y $2004^{14}$, y la Segunda Leyenda, en $2005^{15}$. La obra de Antonio Ubierto Arteta $^{16}$, por su cuidada selección documental, y la de Tomás Sobrino ${ }^{17}$, por su capacidad de síntesis, no deberían pasar desapercibidas en esta recopilación historiográfica.

Una de las obras más relevantes sobre la documentación pontificia, referida al episcopado de cada una de las diócesis del orbe católico, la del conventual franciscano Conrado Eubel $^{18}$, inicia su información en 1198 , con el referido pontificado de Inocencio III. Hasta ese momento, los registros vaticanos se muestran singularmente parcos en documentación seriada. El benedictino Pío Bonifacio Gams ${ }^{19}$, sin más explicaciones, ofreció, en 1873, una lista de prelados abulenses entre 1085 y 1198 difícil de sostener. Hoy no vemos ninguna coherencia entre estos nombres, las fechas y los diplomas que hemos podido analizar.

13 Martín Carramolino, Historia de Ávila, pp. 235-337. Ya hemos indicado que su episcopologio bajomedieval se inicia con Pedro Sánchez Zurraquines, al que habrían seguido los que enumera en una relación que, indica, hace después de haber "corregido algún cambio inexacto en la sucesión»: Sancho; 1133, Suero; Juan; 1133, Íñigo; 1149, Pedro II; Sancho II; 1159, Diego. Después, ańade, «aquí ya aparece claro el catálogo para llegar a don Sancho Dávila, el de Alfonso VIII». En 1182, agregó al obispo Domingo Blasco y a sus sucesores, Diego II, entre 1182 y 1187; Domingo, entre 1187 y 1190; y Diego III, entre 1190 y 1196. Los datos, de nuevo, son difíciles de fijar.

14 Barrios García, Ángel. Documentación medieval de la catedral de Ávila. Salamanca: Ediciones Universidad de Salamanca, 1981; ÍD. Documentos de la catedral de Ávila (siglos XII-XIII). Ávila: Ediciones de la Institución Gran Duque de Alba, 2004.

15 Barrios García, Ángel (ed.). Segunda Leyenda de la muy noble, leal y antigua ciudad de Ávila. Ávila: Institución Gran Duque de Alba, 2005.

16 Ubieto Arteta, Antonio. Listas episcopales medievales. 2 vols. Zaragoza: Anubar Ediciones, 1989.

17 Sobrino Chomón, Tomás. «La Iglesia de Ávila. El territorio, los orígenes discutidos y la época medieval». En Egido López, Teófanes (ed.). Historia de las diócesis españolas. Vol. 18, Iglesias de Ávila, Salamanca y Ciudad Rodrigo. Madrid: Biblioteca de Autores Cristianos, 2005, pp. 5-60.

18 Eubel, Conradum. Hierarchia catholica Medii Aevi sive summorum pontificum, sacra romana Ecclesia cardinalium ecclesiarum antistitum series ab anno 1198 usque ad annum 1431 perducta e documentis tabularii praesertim Vaticani collecta, digesta, edita. 2.a ed. Patavii: Il Messaggero di S. Antonio, 1923. Vid. ASV, Sale Sixto V, XXXIII, I.1.

19 Gams, Pius Bonifacius. Series episcoporum Ecclesiae catholicae quot quot innotuerunt a beato Petro apostolo. Ratisbonae: Typis et sumtibus Georgii Josephi Manz, 1873. La obra fue reeditada en 1957. Vid. ASV, Sale Sixto V, XXXIII, G.1. La relación que ofrece este autor, de la que no ofrece explicación alguna, es la que sigue: 1087, Dominicus. Hoc tempore cathedralis construitur; Hieronymus; 1124, Petrus Sanchez Curraquines, consecratur Compostellae circa 1121, sedet; 1130, sedet; Suero; 1133, 25.VII, consecratur Ioannes; 1142, sedet Innicus; 1153, Petrus II; 1159, Didacus, de Luna (Luco); Sancius II, sub Lucio III; Dominicus, Blasco II (†) 1182; Didacus II ( $\dagger$ ) 1187; Dominicus IV (?) (†) 1190; 1196, sedet; Didacus III (†) 1203. Como veremos en la propuesta de interpretación que formulamos más adelante, se podrían aceptar los ministerios de Domingo Blasco (1182-1187), de Domingo II (1187-1190) y, sobre todo, del obispo Jerónimo de Perigord. El resto, parece recogerlos de los autores anteriores, trasladando así sus mismos errores. 
LA RESTAURACIÓN DE LA DIÓCESIS DE ÁVILA Y EL EPISCOPADO DE LA REPOBLACIÓN (1085-1198) JOSÉ ANTONIO CALVO GÓMEZ

En la obra Bullarum Romanum sobre los principales documentos pontificios, elaborada por los profesores de algunos colegios romanos ${ }^{20}$, en particular, después de la muerte de Gregorio VII, en 1085, no se conserva ningún texto referente a Ávila de los pontificados de Víctor III (1086-1087), Urbano II (1088-1099), Pascual II (1099-1118) ni de ningún papa hasta 1198, aunque se sabe que estos papas remitieron algunas cartas a otros prelados, como al arzobispo de Tarragona (Urbano II: $1089^{21}$ y $1091^{22}$; Gelasio II: $1118^{23}$; Calixto II: $1122^{24}$ ) y al primado de Toledo (Pascual II: $1101^{25}$; Calixto II: $1122^{26}$; Lucio II: $1144^{27}$; Eugenio III: $1152^{28}$; y Adriano IV: $1156^{29}$ ). A ellos, habría que añadir el privilegio de Urbano II al arzobispo Bernardo de Toledo en 109930; las letras ejecutorias

20 Bullarum diplomatum et privilegiorum sanctorum romanorum pontificum. Taurinensis editio. Locupletior facta. Collectione novissima plurium brevium, epistolarum, decretorum actorumque S. Sedis a s. Leone Magno usque ad praesens. Vol. II, Ab Alexandro II (an. MLXI) ad Alexandrum III (an. MCLXXXI). Augustae Taurinorum: Sebastiano Franco et filiis editoribus, 1865. Vid. ASV, Sale Sixto V, XXXI, A. 2. Vol. III, Ab Lucio III (an. MCLXXXI) ad Clementem IV (an. MCCLXVIII). Augustae Taurinorum: Sebastiano Franco et filiis editoribus, 1868. Vid. ASV, Sale Sixto V, XXXI, A. 3, no hay documentación referente a España anterior al pontificado de Inocencio III quien, en 1210, confirma el primado del arzobispo Rodrigo y su jurisdicción metropolitana sobre los obispos de Osma, Palencia, Segovia y Sigüenza. Vid. Bullarum privilegiorum ac diplomatum Romanorum Pontificum amplissima collectio cui accessere pontificum omnium vitae, notae et indices opportuni. Vol. II, Ab Alexandro II ad Alexandrum III, scilicet ab an. MLXI ad MCLXXXI. Romae: Typis S. Michaelis ad Ripam, 1739. Vid. ASV, Sale Sixto V, XLIII, A. 2. Vol. III, A Lucio III ad Clementem IV, scilicet ab an. MCLXXXI ad an. MCCLXVIII. Romae: Typis et sumptibus Hieronymi Mainardi, 1740. Vid. ASV, Sale Sixto V, XLIII, A. 3.

21 Ibidem, fols. 124-125: De reparatione Ecclesia Tarraconensis, cuius favore ea impendi conceditur, quae necessaria forent ituris in Hierusalem, vel in alias partes.

22 Ibidem, fols. 136-138: Tarraconensis Ecclesia, civitate nuper ab Agarenorum manibus vindicata, Ausonem. episcopis comittitur, usquedum pristino statui ac splendori reddatur.

${ }_{23}$ Ibidem, fols. 283-284: Oldegario Barchinonensi episcopo, ad Tarraconensem Ecclesiam translato, archiepiscopatus et ius metropolicum confirmatur, palliumque conceditur.

24 Ibidem, fols. 323-324: Oldegarius, Tarraconensis achiepiscopus, legatus Sedis Apostolicae ad exercitum, contra Saracenos in Hispaniis paratum, constituitur.

25 Ibidem, fols. 214-216: Confirmatio primatus Toletanae Ecclesiae supra caeteras omnes Hispaniarum Ecclesias. No especifica las iglesias sufragáneas sujetas al arzobispo Bernardo, entre las que todavía no estaría Ávila a la espera de ser restaurada en la persona de Jerónimo de Perigord.

26 Ibidem, fols. 326-327: Confirmatio dignitatis primatialis Toletanae Ecclesiae, cum declaratione, ut eidem subiectae sint Hispaniarum Ecclesiae omnes, quae suos amiserunt episcopos post saracenorum incursiones, en que confirma al arzobispo Bernardo la condición de primado y se enumeran sus iglesias sufragáneas: Oviedo, León y Palencia, además de la antigua sede complutense, «salvo tenore privilegii, quod a nobis Compostellae Ecclesiae Pontifici est collatum», sin mención alguna de la Iglesia abulense.

27 Ibidem, fols. 495-496: Confirmatio dignitatis primatus Toletanae Ecclesiae, que confirma el primado al arzobispo Raimundo sin especificar las iglesias sufragáneas de su jurisdicción metropolitana.

28 Ibidem, fols. 576-578: Confirmatio primatus Toletanae Ecclesiae super caeteras Ecclesias Hispaniarum. Sequitur ad Hispaniarum episcopos in indem argumentum, que confirma el primado al arzobispo Juan, su jurisdicción directa sobre las parroquias de la antigua diócesis complutense, y su autoridad metropolitana sobre las sedes de Osma, Palencia, Segovia y Sigüenza.

29 Ibidem, fols. 629-630: Confirmatio primatus Toletanae Ecclesiae cui Complutensis, et quae post saracenorum invasionem proprios amisere metropolitas, subiiciuntur. Domínguez Sánchez, Santiago. Documentos pontificios referentes a la diócesis de León (siglos XI-XIII). León: Universidad de León, 2003, pp. 72-73, indicó que debía fecharse en 1121, según el cómputo pisano del tercer año del pontificado de Calixto II.

30 Ibidem, fols. 62-63. Por este privilegio, Urbano II declaraba que estaban sometidas a la jurisdicción metropolitana del arzobispo Bernardo tanto la Complutensem parroquiam, como las diócesis de Oviedo, León y Palencia. No aparece Ávila. 
LA RESTAURACIÓN DE LA DIÓCESIS DE ÁVILA Y EL EPISCOPADO DE LA REPOBLACIÓN (1085-1198) 162 JOSÉ ANTONIO CALVO GÓMEZ

de Calixto II de 1121-1123 31 ; y el privilegio de Honorio II, en $1125^{32}$, que Santiago Domínguez publicó en 2003. En 1114, Bernardo de Cluny, arzobispo de Toledo, escribió a Diego Gelmírez, de Compostela, para que pidiera a los obispos sufragáneos de Braga que no prestaran obediencia a su metropolitano hasta que este no renunciara a la diócesis de León, que había ocupado con el apoyo del rey Alfonso I el Batallador, de Aragón ${ }^{33}$. Se citan algunos conflictos, resueltos en tiempo de Inocencio II en $1133^{34}$ y $1135^{35}$, en los que intervinieron los arzobispos de Compostela y Toledo; pero no se hace mención, en ningún momento, a la diócesis abulense.

También nosotros queremos hacer nuestra aportación, resultado de un proyecto de investigación financiado, durante el curso 2016-2017, por el Instituto Español de Historia Eclesiástica, anejo a la Iglesia Nacional de Santiago y Montserrat, de Roma, dependiente del Ministerio de Asuntos Exteriores. El proyecto llevaba por título «El clero secular en la Edad Media. El episcopado abulense de la repoblación bajomedieval (10851198) según la documentación del Archivo Secreto Vaticano». Entre otras aportaciones, veremos que los profesores romanos, autores del Bullarum Romanum, a mediados del siglo XIX, dejaron algunos documentos sin estudiar que, referentes a la diócesis de Ávila en este periodo, hemos podido localizar entre los fondos del Archivo Secreto Vaticano ${ }^{36}$.

2 El itinerario para la restauración de la iglesia abulense. Jerónimo de PeRIGORD, ADMINISTRADOR DESDE 1103 A 1120

Según la información que se puede obtener de la documentación, la lista de prelados abulenses para este momento histórico de la repoblación bajomedieval castellana sería

31 Ibidem, fols. 74-75. Por esta carta, Urbano II comisionó a los obispos de Palencia, Oviedo, León y Salamanca para que examinaran la vida y costumbres del electo de Burgos, y proceder, si fuera el caso, a su consagración. Después de la muerte de Jerónimo de Perigord, se habría consagrado, en 1120, un nuevo obispo para Ávila y otro para Salamanca, que no se nombran.

32 Ibídem, fols. 76-77. Por este privilegio, Honorio II ratificó a Raimundo de Toledo la primacía de las iglesias peninsulares y su jurisdicción sobre la parroquia complutense y las diócesis de Oviedo, León y Palencia.

33 Ibidem, fols. 66-67. No hay mención de la diócesis abulense. Sobre el conflicto entre Braga y Toledo por el episcopado de León, vid. la obra clásica: David, Pierre. Études historiques sur la Galice et le Portugal: du VIe au XIt siècle. Lisboa: Livraria Portugália, 1947.

34 Ibidem, fol. 78.

35 Ibidem, fols. 78-79.

36 En 2016, vio la luz una nueva monografía sobre este tema, con el mismo marco cronológico de nuestra investigación: Engel, Frank y Martín Martín, José Luis (eds.). Iberia Pontificia sive repertorium privilegiorum et litterarum a romanis pontificibus ante annum MCLXXXXVIII Hispaniae et Portugalliae ecclesiis, monasteriis, civitatibus singulisque personis concessorum. Vol. IV, Provincia Compostellana. Dioeceses Abulensis, Salmanticensis, Cauriensis, Civitatensis, Placentina. Göttingen: Vandenhoeck \& Ruprecht, 2016. En esta obra, se presenta un exhaustivo elenco de los diplomas pontificios que atañen al territorio abulense durante los siglos XI y XII, sobre todo a sus prelados. Junto a los 127 registros sobre los obispos, se recogen numerosas referencias documentales a laicos y clérigos de esta Iglesia, así como a algunas instituciones religiosas, sobre todo a las órdenes militares y a la catedral. En las páginas 3-8, se aborda una sucinta relación prosopográfica de sus obispos que, para estos siglos, confirma una cronología que, a pesar de las dudas de la historiografía de los siglos anteriores, parece que debería aceptarse ya como definitiva. 
la siguiente: Jerónimo de Perigord (administrador desde 1103-1120); Sancho I (11211133); Íñigo (1133-1158); Sancho II (1160-1181); Domingo I (1182-1187); Domingo II (1187-1190); y Juan I (1191-1195). Al obispo Juan le sucedería Jacobo (1195-1203), más allá de los límites cronológicos que nos hemos dado, que actuaría, sobre todo, durante el pontificado de Inocencio III.

Como hemos presentado en las fuentes historiográficas, existen numerosas discrepancias en varios momentos. En 1120, a la muerte de don Jerónimo, aparece citado cierto Pedro Sánchez Zurraquines como obispo de Ávila; en 1149, se menciona un segundo Pedro; en 1156, encontramos un obispo llamado Enrique y, en otra fuente, en esta misma época, a cierto Juan; en 1172, se cita al obispo Domingo; en 1184, aparece en esta sede un tercer obispo Pedro; y en 1187, se cita a Gomes como prelado de esta ciudad. Habría más. Veremos que estas dudas apenas tienen fundamento en las fuentes diplomáticas. En muchos casos, la noticia de estos supuestos obispos la ofrecen fuentes secundarias o listas de confirmantes en diplomas estandarizados que, con frecuencia, por el afán de fortalecer ciertas cláusulas, añadían nombres de prelados sin crítica prosopográfica de ninguna clase.

El desarrollo de los acontecimientos, la actuación de los protagonistas de la jerarquía castellana después de 1085 y, sobre todo, la trasformación de una realidad eclesial que, a finales del siglo XI, se revelaba fundamentalmente arruinada, desmantelada, desestructurada y, cien años después, junto a la promoción de la vida cristiana, había emprendido, con éxito, la construcción de numerosos edificios civiles y fundamentalmente religiosos, incluida una nueva catedral, podría explicarse, como veremos, aludiendo a un cierto análisis crítico. En 1050, según se recoge en la Primera Crónica General, el rey leonés, Fernando I (1037-1065),

porque uio que la cibdad de Áuila estaua despoblada et yerma de luengos tiempos dantes, et esto por el destruymiento de los moros, tomó ende los cuerpos de los mártires santos sant Vicent et santa Sabina et santa Cristeta, et leuó el cuerpo de sant Vicente con una gran partida de las reliquias de aquellas dos hermanas pora León, et metiolas en una arqueta, et pusolas cerca el cuerpo de sant Esidro ${ }^{37}$.

La realidad eclesial, aunque ciertamente presente en los piadosos cristianos que habían conservado los restos y la memoria de los tres santos hermanos mártires, se manifestaba, en el transcurso de los siglos, singularmente maltrecha. Resulta evidente que no existía, para entonces, ninguna autoridad jerárquica y que esta llegaría solamente después de muchas décadas, con la consolidación de la presencia cristiana, durante el reinado de su hijo, el rey Alfonso VI de León y Castilla. Según los datos que manejamos, Jerónimo de Perigord (1103-1120), de origen francés, después de actuar durante algunos ańos en Valencia (1094-1102), habría recibido el encargo de Raimundo de Borgoña, yerno del rey, de restaurar las diócesis de Salamanca y Ávila ${ }^{38}$. Sus gestas fueron moduladas en el Cantar del Mío Cid, en estas letrillas:

37 Menéndez Pidal, Ramón (ed.). Primera crónica general. Estoria de España que mandó componer Alfonso el Sabio y se continuaba bajo Sancho IV en 1298. Madrid: Bailly Baillière e Hijos, 1906, p. 491.

38 No se conserva ningún documento de este prelado en ASV. Vid. Ref. Schedario Garampi 31, Índice 475, Vescovi 1, fol. 48v (Abulensis); Ref. Schedario Garampi 61, Índice 505, Vescovi 31, fol. 84v 
LA RESTAURACIÓN DE LA DIÓCESIS DE ÁVILA Y EL EPISCOPADO DE LA REPOBLACIÓN (1085-1198) 164 JOSÉ ANTONIO CALVO GÓMEZ

En estas nueuas, todos se a alegrando/ de parte de orient, vino vn coronado/ el obispo don Ierónimo so nombre es lanmado/ bien entendido es de letras y mucho acordado/ de pie y de cauallo mucho era areziado/ las pruezas de Mýo Çid andáualas demandado/ sospirando el obispo que se viesse con moros en el campo/ qui sis fartas lidiando y firiendo con sus manos/ a los días del sieglo non le lorassen christianos ${ }^{39}$.

Según esta conexión con el Cid, don Jerónimo habría venido desde Francia y, en premio de su apoyo, habría recibido del Campeador ciertas propiedades en los alrededores de Valencia, a finales de 1093 o principios de 1094. A mediados de 1094, habría entrado con el conquistador en la capital del Turia y, tras su consagración en Roma por el papa Urbano II, habría regresado para restaurar la Iglesia valentina tras su recuperación del islam. De allí, siempre según cierta interpretación, habría partido tras la pérdida de la plaza, en 1102, en dirección a las ciudades de Zamora y Salamanca, para proceder a la sucesiva rehabilitación de las maltrechas sedes leonesas y, desde 1103, también la de Ávila ${ }^{40}$.

En otra versión, algo interesada, en otro sentido, se recogen sus actuaciones, de la mano del arzobispo Bernardo de Toledo, en la crónica de Rodrigo Jiménez de Rada, De rebus Hispaniae, redactada a principios del siglo XIII, que ha sido reeditada hace unos años $^{41}$. Según esta computación, tras el concilio de Burgos de 1080, Jerónimo, al que se le hace pertenecer a la Orden de San Benito, habría venido de la mano del nuevo arzobispo de la reconquistada Toledo para implantar el rito romano en sustitución del desautorizado rito visigodo o mozárabe, todavía en uso. Esta segunda versión, que podríamos denominar «toledana», menos probable, interesada, podría estar en relación con la pretendida dependencia de la ciudad abulense de la sede primada y el conflicto que se resolvió, contra Santiago de Compostela y contra Mérida, en el control de las Iglesias de los Extrema Durii castellanos.

En cualquier caso, durante este primer pontificado de la restaurada sede abulense, la ciudad, poco a poco, vio erigir las primeras iglesias. En una donación al monasterio de San Millán de la Cogolla, datada en 1103, se citan ya las parroquias de San Vicente, San Pedro y San Martín ${ }^{42}$. Ángel Barrios menciona un documento de Alfonso VII de León, el Emperador (1126-1157), que indica que «avilensis ecclesia titulo Sancti Saluatoris

(Salmanticensis). Pero no hay dudas sobre su ministerio en Ávila. Vid. Serrano, Luciano. Cartulario de San Millán de la Cogolla. Madrid: Centro de Estudios Históricos, 1934, p. 294. No lo recoge Cianca; pero sí Ariz, fol. 34v; González Dávila, fol. 226r; y Tello, p. 126.

39 BN. Sección Manuscritos. Fondo Marqués de Pidal, Mío Cid, fol. 27r, versos 1297-1295. Para una versión modernizada, vid. Montaner Frutos, Alberto. http//:caminodelcid.org (consulta: 2018.10.12). Allí dice: «Con estas novedades, todos alegres estando/ de la parte de oriente vino un tonsurado,/ el obispo don Jerónimo por nombre es llamado,/ muy entendido es en letras y muy ponderado,/ a pie y a caballo es muy esforzado./ Por las proezas de mío Cid andaba preguntando,/ suspirando el obispo por verse con los moros en el campo,/ pues si se hartase luchando e hiriendo con sus manos,/ al final de su vida no le llorarían los cristianos".

40 Lacombe, Claude. Jerónimo de Perigueux (¿1060?-1120). Obispo de Valencia y de Salamanca. Un monje caballero en la reconquista. Salamanca: Universidad Pontificia de Salamanca, 2000.

41 Jiménez de Rada, Rodrigo. Historia de los hechos de España, ed. de Juan Fernández Valverde. Madrid: Alianza: 1989.

42 Serrano, Cartulario de San Millán, pp. 294-296. 
adtitulata [...] modernis temporis a meo genitore nobiliter edificata ${ }^{43}$. La reconquista militar, la repoblación y la restauración de la Iglesia fueron de la mano, bajo el gobierno de Raimundo de Borgoña, en una combinación en la que el propio prelado, don Jerónimo, parece que tuvo, también, un protagonismo singular.

Junto a él, se cuenta que actuó cierto prelado, Pedro Sánchez Zurraquines, que, en algunos autores, apareció, ya lo sabemos, como titular de la sede a la muerte de Jerónimo de Perigord; pero no hay ninguna prueba documental ni en el Archivo Secreto Vaticano ni en las diversas recopilaciones documentales que hemos manejado. Las crónicas del siglo XVII, sobre todo Ariz y Gil González Dávila, pudieron haber confundido cierta actividad de Sánchez Zurraquines en la ciudad del Adaja, como representante del prelado salmantino, como si del depositario de la mitra abulense se tratara ${ }^{44}$.

La leyenda en torno a don Jerónimo se completa con algunos datos más sobre su participación junto al Cid en su obra militar. A la muerte del Campeador, el prelado recibió el Cristo que le acompañaba en sus batallas. Hoy, el primer obispo de Ávila tras la restauración yace en la catedral de Salamanca, que él mismo promovió, en la capilla del Cristo de las Batallas del Cid. En primera instancia, don Jerónimo fue enterrado en la catedral vieja. Tras la erección de la nueva seo, el año 1607, fue trasladado a su ubicación actual, junto con el Cristo que ya, en la vieja catedral románica, daba nombre a la capilla que contenía sus restos.

\section{Los siete sucesores de don Jerónimo, en Ávila, durante el siglo XII}

A la muerte de don Jerónimo, el 30 de junio de $1120^{45}$, tanto la diócesis de Salamanca, en la persona de Giraldo; como la de Zamora, en la de Bernardo de Perigord; y, en lo que nos atañe, la Iglesia de Ávila, en la de Sancho I (1121-1133), contaron ya con sendos prelados para regir sus destinos. De la actividad del obispo Sancho, en Ávila, ha quedado una extensa memoria documental entre los fondos manuscritos y editados del Archivo Secreto Vaticano y en otras fuentes diplomáticas, desde su elección, en 1120, hasta su muerte, en $1133^{46}$.

43 Barrios García, Ángel. La catedral de Ávila en la Edad Media. Estructura socio-jurídica y económica (bipótesis y problemas). Ávila: Obra Social y Cultural de la Caja Central de Ahorros y Préstamos de Ávila, 1973, p. 101.

44 Esta polémica historiográfica fue seguida de cerca por Belmonte Díaz, José. La ciudad de Ávila. Estudio histórico. 3. ${ }^{a}$ ed. Ávila: Caja de Ahorros de Ávila, 1997, pp. 93-100. Tampoco hay razones para pensar en la existencia de un único obispo llamado Domingo, datado hacia 1082-1090 por la Crónica de la Población de Ávila; ni de cierto Sancho, hacia 1115, sucesor de Jerónimo, que habría asistido, según Belmonte, al concilio de Oviedo de aquella fecha.

45 Sobrino Chomón, «La Iglesia de Ávila. El territorio», p. 13.

46 Vid. Lucas Álvarez, Manuel. Colección diplomática de San Martín Pinario (manuscrito), doc. 79 (22 de marzo de 1122); Minguella y Arnedo, Toribio. Historia de la diócesis de Sigüenza y de sus obispos. Madrid: Imprenta de la Revista de Archivos, Bibliotecas y Museos, 1910, vol. 1, p. 353, doc. 6, de 7 de febrero de 1130. Lo menciona Cianca, fols. 78v-79r, aunque antepone a cierto Juan, en 1133. Ariz habló de él ya en 1115, apoyado en un falso histórico. En ASV, aparecen numerosas indicaciones: 1120: Sancius, abulensis episcopus. Consecratur. Vid. Flórez, España sagrada, t. XXI, p. 65. Ref. Schedario Garampi 31, Indice 475, 
LA RESTAURACIÓN DE LA DIÓCESIS DE ÁVILA Y EL EPISCOPADO DE LA REPOBLACIÓN (1085-1198) 166 JOSÉ ANTONIO CALVO GÓMEZ

Antes de la consagración del obispo Sancho, insistimos, algunos autores, como Gil González Dávila o Tello mencionaron la existencia de cierto «Petrus, electus episcopus abulensis», que quisieron identificar, de nuevo, con Pedro Sánchez Zurraquines. En cualquier caso, no llegó a tomar posesión y, en 1121, Sancho I fue ordenado en Santiago por el arzobispo Diego Gelmírez (1096-1140), protagonista indiscutible de este periodo de la repoblación castellanoleonesa y de la reorganización de la Iglesia en la Península Ibérica. La Historia Compostelana, aunque redactada para gloria del arzobispo compostelano, no deja de ser una fuente para este periodo $y$, en lo que a sus datos preterintencionales se refiere, se torna fundamental en la confirmación de algunas noticias dispersas que afectan a la marcha de la Iglesia abulense en los primeros años del siglo xII. El papa Calixto II (1119-1124), precisamente en 1120, elevó la Iglesia compostelana a la categoría de sede metropolitana y le adscribió las antiguas diócesis de la provincia emeritense, todavía bajo dominio musulmán. La polémica con el arzobispo Bernardo de Cluny, que consagró al obispo Giraldo de Salamanca, estaba ampliamente servida ${ }^{47}$. El prelado toledano acusó a Gelmírez de consagrar al obispo Sancho I después de haber sido elegido, no por el clero, como era preceptivo, sino a suertes, por «laicos ignorantes». En su defensa, Gelmírez arguyó que esta elección había sido confirmada por dos arzobispos, nueve obispos y un legado apostólico.

En años posteriores, Sancho de Ávila se hará presente en las reuniones de los obispos sufragáneos con el arzobispo Gelmírez, que lo fue hasta su muerte, en $1140^{48}$. Sobre el final de su pontificado en Ávila, en 1133, Tomás Sobrino recoge cierta noticia de José María Quadrado ${ }^{49}$, muy significativa:

Vescovi 1, fol. 48v, scheda 10. Años 1120, 1124: Abulensis Ecclesia sit suffraga. Compostelanus. P<etrus> electus. Vid. Flórez, España sagrada, t. XX, pp. 293, 308, 403, 406. Ref. Schedario Garampi 31, Indice 475, Vescovi 1, fol. 48v, scheda 13. Años 1121, 1124: Sancius, abulensis episcopus. Consecratur. Vid. Flórez, España sagrada, t. XX, pp. 322, 359, 395. Ref. Schedario Garampi 31, Indice 475, Vescovi 1, fol. 48v, scheda 11. Año 1126: Abulensis episcopus. Vid. Flórez, España sagrada, t. XX, p. 434. Ref. Schedario Garampi 31, Indice 475, Vescovi 1, fol. 49r., scheda 1. Años 1128, 1130: Sancius, abulensis episcopus. Vid. Flórez, España sagrada, t. XX, pp. 468, 500. Ref. Schedario Garampi 31, Indice 475, Vescovi 1, fol. 49r., scheda 2. Año 1133: Defuncto Sancio, episcopus abulensis. In eius locum, a clero eligitur Eneco et ab archiepiscopus Compostelanus consecratur. Vid. Flórez, España sagrada, t. XX, pp. 532, 539, 541, 545, 565. Ref. Schedario Garampi 31, Indice 475, Vescovi 1, fol. 49r., scheda 3.

47 Rivera Recio, Juan Francisco. El arzobispo de Toledo don Bernardo de Cluny. Roma: Instituto Español de Historia Eclesiástica, 1962.

48 Vid. Historia Compostelana, pp. 322-323, donde se menciona, en 1221, al obispo electo de Ávila confirmado por el cardenal legado, por los nueve obispos firmantes y por los dos arzobispos. El prelado abulense indicó: «Ego Sancius, Abilensis (sic) Ecclesiae ordinandus episcopus subjectionem et reverentiam et obedientiam a Sanctis Patribus constitutam secundum praecepta canonum Ecclesiae Compostellanae, rectoribusque eius in praesentia domini archiepiscopi $\mathrm{D}<$ idacus $>$ perpetuo me exhibiturum promito et supra sanctum altare propria manu confirmo». En las pp. 394-395, se transcribe la confirmación de la bula de Calixto II por la que se constituyó la sede metropolitana de Santiago de Compostela, a la que había jurado estar sujeto, dos ańos antes, el obispo Sancho de Ávila.

49 Quadrado, José María. Salamanca, Ávila y Segovia. Barcelona: Daniel Cortezo y Compañía, 1884, pp. 341-343. Sobrino Chomón, «La Iglesia de Ávila. El territorio», p. 14, menciona que el documento no lleva fecha; pero cree que se debe datar el año 1133, cuando ya ha muerto el obispo Sancho y todavía no ha sido elegido su sucesor, Íńigo, ya que no se nombra, en el texto, a ninguno de los dos. En realidad, el documento, que se conserva en una copia coetánea (AHN. Sección Clero. Pergaminos carp. 18, n. ${ }^{\circ} 1$ ) fue 
Creemos que, hasta su pontificado, la Iglesia abulense, al contrario que la salmantina, arrastraba una vida precaria. Un documento por el que Alfonso VII dona a la Catedral abulense la tercera parte de los derechos regios, al igual que su padre había hecho con la salmantina, nos describe la sede abulense como 'valde destructam et pene ab omni libertate exclusam [...] a pastore et ovibus orbata' e invoca las bendiciones del cielo sobre todos los que cooperen en su reconstrucción.

A la muerte de Sancho, fue designado para sucederle, por unanimidad, su hermano Ínigo (1133-1158), arcediano de la Catedral, que aparece en algunos diplomas contemporáneos $^{50}$. Así se lo relata el propio obispo electo al arzobispo Gelmírez y así quedó inmortalizado en la Historia Compostelana ${ }^{51}$ : «Conuentu factu, omnis clerus [...], populis petiuit, rex anuit [...] et quia onmes unanimes esse et unitatem in electionem mei servare cognoui, electioni eorum si vestrae adsit consensum sanctitatis, consentivi». Según este relato, el obispo de Segovia, que presidió los funerales del difunto Sancho, también asistió a la elección de su sucesor, el canónigo Ínigo, consagrado por el arzobispo Gelmírez, en Compostela, en 1133. Su pontificado duró hasta 1158, según confirman los datos que se conservan en el Archivo Secreto Vaticano ${ }^{52 .}$

reseñado por Ángel Barrios en 1981 y, posteriormente, el mismo autor transcribió su contenido en 2004. Vid. Barrios García, Documentación medieval de la catedral de Ávila, p. 3; ÍD., Documentos de la catedral de Ávila, pp. 23-23. Sobre la sepultura del prelado, ańade Sobrino en nota: «En el siglo Xv, su sepultura se localiza en el presbiterio: El obispo don Diego, en el coro, ante el altar, en par de la sepultura del obispo Sancho, el primero (Libro de Óbitos, cod. 914B del AHN, a 10 de enero). Ello nos hace dudar de la inscripción sepulcral: "don Sancho el primero; no se halla el año que murió, por ser muy antiguo” que en el siglo xvi se colocó sobre otro sepulcro que, según el mismo obituario, corresponde a "el obispo don Sancho, el segundo, altar de Santa María, a mano izquierda” (Id., a 20 de febrero)». Lo cierto es que tanto Cianca como Tello ya advirtieron de la posible equivocación y de la posible transliteración entre Sanctius Secundus y Sanctus Secundus. Vid. la polémica en Rodríguez Almeida, Emilio. El cáliz de san Segundo. Ávila: Institución Gran Duque de Alba, 1997, pp. 75-77. Almeida no se extrañaba de estas dificultades porque, como él mismo reconocía, «es sabido que el episcopado abulense de la primera repoblación presenta infinitas incertidumbres, añadidos, lagunas, errores, y que solamente a partir de la segunda mitad del siglo XIII comenzamos a estar razonablemente seguros de datas, nombres y secuencia».

50 Serrano, Luciano. Cartulario de San Pedro de Arlanza. Madrid: Centro de Estudios Históricos, 1925, p. 187, doc. 97, de 26 de mayo de 1135; Colmenares, Diego de. Historia de la insigne ciudad de Segovia y compendio de las historias de Castilla. Segovia: Eduardo Baeza, 1869, vol. 1, p. 141. Lo mencionan Cianca, fol. 78v; Ariz, fol. 36v; González Dávila, fol. 243; y Tello, pp. 145-146.

51 Historia Compostelana, pp. 536-542. Se recoge aquí la carta que, a la muerte del obispo Sancho, envió la ciudad de Ávila al arzobispo; la que remitió el electo Íñigo; la respuesta del arzobispo al clero y a los laicos, hijos de la Iglesia de Ávila; la respuesta al electo Íñigo; la confirmación del rey Alfonso VII; la memoria de la consagración del prelado; y el juramento que otorgó en las manos de Gelmírez. Es similar al que firmó su hermano Sancho: «Ego, Ennecus, sancta Abilensis (sic) Ecclesiae nunc ordinandus episcopus subjectionem et reverentiam et obedientiam a $\mathrm{S}<$ anctis $>$ Patribus constitutam secundum praecepta canonum Ecclesiae $\mathrm{B}<$ eati> Iacobi rectoribusque eius in prasentia domini Dicadi, archiepiscopi perpetuo, me exhibiturum promitto et super sanctum altare propria manu confirmo».

52 Año 1133. Defuncto Sancio, episcopus abulensis. In eius locum, a clero eligitur Eneco et ab archiepiscopus compostelanus consecratur. Vid. Flórez, España sagrada, t. XX, pp. 532, 539, 541, 545, 565. Ref. Schedario Garampi 31, Indice 475, Vescovi 1, fol. 49r, scheda 3. Año 1142. Ennecus abulensis episcopus. Vid. Flórez, España sagrada, t. XVII, p. 89. Ref. Schedario Garampi 31, Indice 475, Vescovi 1, fol. 49r, scheda 4. Año 1154. Enegus abulensis episcopus. Vid. Flórez, España sagrada, t. XVI, p. 488. Ref. Schedario Garampi 31, Indice 475, Vescovi 1, fol. 49r, scheda 7. Año 1156. Enecus avilen. episcopus 
LA RESTAURACIÓN DE LA DIÓCESIS DE ÁVILA Y EL EPISCOPADO DE LA REPOBLACIÓN (1085-1198) 168 JOSÉ ANTONIO CALVO GÓMEZ

También se confirma su actuación por numerosos diplomas de los que dejó constancia Ángel Barrios en la Documentación medieval de la Catedral de Ávila. En estos documentos se verifica, sobre todo, la confirmación de algunas propiedades, como las que sellan los papas Inocencio II (1130-1143), en 1140; y Eugenio III (1145-1153), en 1148; y la llegada de donaciones importantes a favor de la Catedral, sobre todo del rey Alfonso VII (1126-1157), en 1142 y en 1144; y de algunos particulares, como Juan Gómez, en 1146; y Justo y María, su mujer, en $1150^{53}$. En 1155, sin embargo, la documentación del Archivo Vaticano indica que era obispo de Ávila cierto Enrique, fruto evidente de un error de interpretación diplomática ${ }^{54}$.

Ariz $^{55}$, en este periodo, bajo el gobierno del obispo Íñigo, cita a cierto Juan que, según el libro de óbitos del monasterio de la Espina, habría sido obispo de Ávila y, a su muerte, habría querido ser trasladado a este monasterio para ser enterrado allí. Ni el libro de óbitos ni el historiador ofrecen datos cronológicos fiables. El mismo Ariz ${ }^{56}$, junto a José María Quadrado ${ }^{57}$, mencionaba ya, para 1149, a un segundo prelado llamado Pedro, que habría participado en la consagración del monasterio de San Isidoro de León. Ninguno de estos tres presuntos obispos, Enrique, Juan y Pedro, presentan verosimilitud histórica alguna. Apenas sostiene su existencia una noticia aislada, sin verdadero respaldo documental que pudiera contradecir la tesis principal, es decir, que Ínigo, hermano menor de Sancho I, ejerció el ministerio episcopal en Ávila desde 1133 hasta su muerte, ocurrida en 1158.

Durante este tercer pontificado, verdaderamente prolongado en el tiempo, se podría decir que se llega a consolidar la vida de la Iglesia en Âvila en cuatro aspectos fundamentales, al menos: la organización territorial, la estructura de la Catedral, la erección de nuevos monasterios y el florecimiento de la vida anacoreta. De todo ello dan buena cuenta los trabajos de Tomás Sobrino ${ }^{58}$. En cuanto a la organización territorial, cabe mencionar que, en 1147, se crea el arcedianato de Olmedo y, hacia 1157, el de Arévalo. La región llana de la diócesis abulense, la más poblada, a la retaguardia de la reconquista, exigió una

(abulensis). Vid. Flórez, España sagrada, t. XVIII, p. 354. Ref. Schedario Garampi 31, Indice 475, Vescovi 1, fol. 49r, scheda 5. Año 1157. Enego abulensis episcopus. Vid. Flórez, España sagrada, t. XVII, p. 255. Vid. Schedario Garampi 31, Indice 475, Vescovi 1, fol. 49r, scheda 6.

53 Barrios García, Documentación medieval de la catedral de Ávila, pp. 3-9. AC, doc. 1, de 19 de marzo de 1140; AC, doc. 2, de 28 de julio de 1142; BN, Sección Manuscritos, n. ${ }^{\circ}$ 712, fols. 314v-315r, de 27 de septiembre de 1142; AHN, Sección Clero, Pergaminos, carp. 18, n. ${ }^{\circ}$ 4, de noviembre de 1144; AHN, Sección Clero, Pergaminos, carp. 18, n. ${ }^{\circ}$ 5, de 29 de mayo de 1146; AC, doc. 3, de 31 de marzo de 1148; AHN, Sección Clero, Pergaminos, carp. 18, n. ${ }^{\circ}$ 6, de 31 de diciembre de 1150 . Todos estos documentos se refieren a la actuación del obispo Eneco o Íñigo (1133-1158).

54 Año 1155 . Henricus abulensis episcopus. Vid. Manrique, Ángel. Cisterciensium seu verius ecclesiasticorum annalium a condito Cistercio. Lugduni: Sumpt. Haered. G. Boissat \& Laurent Anisson, 1642, vol. I, p. 436. Ref. Schedario Garampi 31, Indice 475, Vescovi 1, fol. 49r, scheda 8. Se trata de la confirmación de un documento de donación de Alfonso VIII (1158-1214) a la iglesia de Santa María de Barcelona y al abad Giraldo. No dice nada más que «Henricus, abulensis episcopus, confirmat». Está datada en Palencia, el 27 de diciembre de 1155 (VI Kalendas Ianuarii era MCXCIII). Vid. ASV, Sale Sixto V. XLVI D1. En ocasiones, este tipo de confirmaciones conllevan evidentes errores prosopográficos.

55 Ariz, Historia de las grandezas, p. 74.

56 Ibidem, p. 75.

57 Quadrado, Salamanca, Ávila y Segovia, pp. 343-380.

58 Sobrino Сhomón, «La Iglesia de Ávila. El territorio», pp. 15-16. 
organización más compleja. En pocos años, la documentación constatará la provisión de algunas parroquias, a las que llegaría un tercio de los diezmos para el sostenimiento del clero y de la fábrica de las iglesias.

En relación con la estructura de la Catedral, Barrios transcribe un documento de $1181^{59}$, más allá de este pontificado, que podría considerarse la prueba material de esta consolidación, obrada en el primer templo abulense durante el ministerio del obispo Ínigo. Según este texto, el obispo Sancho II, del que hablaremos, donó a la Orden de San Juan de Jerusalén la iglesia de Santa María de la Vega, de Olmedo, con sus derechos de ofrenda y oblaciones, así como con un tercio de los diezmos. Entre otras explicaciones, se indicaba que la Iglesia de Ávila contaba ya con un prior, con los arcedianos de Ávila, Arévalo y Olmedo, con un arcipreste, con un cantor o preceptor y con varios canónigos. No cabe duda de que, a mediados del siglo XII, la realidad eclesial distaba mucho de aquella condición de «despoblada et yerma» con que la había descrito el rey Fernando I hacia 1050.

En cuanto a la erección de nuevos monasterios, se podrían citar ciertas crónicas sobre la presencia de los canónigos regulares en Burgohondo desde finales del siglo $\mathrm{XI}^{60}$; pero solo en el año 1179, por bula de Alejandro II, se entregó al obispo la jurisdicción sobre este cenobio y sobre el monasterio de monjes benedictinos de Gómez Román, o La Lugareja, a las afueras de Arévalo, convertido en monasterio de monjas cistercienses a mediados del siglo XIII ${ }^{61}$. A ellos se añadirían pronto los de Santa María de la Antigua y Sancti Spíritus en la misma ciudad de Ávila. Finalmente, sobre el florecimiento de la vida anacoreta, cabe añadir que, entre los eremitas de esta época, destacan los nombres de san Pedro del Barco, san Pascual de Tormellas y san Bernardo de Candeleda, que fueron estudiados por Tello ${ }^{62}$ y hoy han encontrado nuevos intérpretes en la historiografía contemporánea ${ }^{63}$.

Dos años después de la muerte de Íñigo, ocurrida en 1158, fue elegido para sucederle Sancho II (1160-1181) que, según Sobrino Chomón, asistió al tercer Concilio de Letrán, del año $1179^{64}$. La documentación pontificia sobre este prelado, menos conocido por la historiografía nacional, completa algunos datos ${ }^{65}$. Puede llegar a crear algunas

59 Barrios García, Documentación medieval de la catedral de Ávila, pp. 15-17 (doc. 18).

60 Calvo Gómez, José Antonio. «Cuatro crónicas sobre el origen del monasterio de Santa María de Burgohondo (siglo XI)». Salmanticensis, 2009, vol. 56, pp. 315-356.

61 Barrios García, Documentación medieval de la catedral de Ávila, pp. 13-15 (doc. 16, de 21 de abril de 1179).

62 Tello, Cathálogo sagrado, fols. 344-389.

63 Jiménez Duque, Baldomero. Ávila mistica. Ávila: Ediciones de la Obra Cultural de la Caja de Ahorros de Ávila, 1992, p. 20.

64 Sobrino Chomón, «La Iglesia de Ávila. El territorio», p. 16. GonzÁlez, Julio. El reino de Castilla en la época de Alfonso VIII. Madrid: Escuela de Estudios Medievales, 1960, p. 646 (11 de julio de 1160) y p. 664 (15 de noviembre de 1181); Mansi, Joannes Dominicus. Sacrorum Conciliorum nova et amplissima collectio. Florentiae Venetiis: Antonius Zatta, 1778, vol. XXII, pp. 216, 465. Lo cita Tello, aunque antepone cierto Pedro, obispo entre 1142 y 1149 ; un segundo Sancho, en 1150; y cierto Pedro, en 1159. También lo menciona Cianca, fol. 79r; Ariz, fol. 37r; González Dávila, fol. 245; Tello, pp. 48-49.

65 Año 1179. Sanctius abulensis episcopus. Vid. Manrique, Cisterciensium seu varius ecclesiasticorum annalium, vol. III, p. 85. Ref. Schedario Garampi 31, Indice 475, Vescovi 1, fol. 49r, schede 9 e 13 (aquí cita por error el t. VII, p. 85, que no existe). Se trata de la confirmación de un documento de donación de Alfonso 
LA RESTAURACIÓN DE LA DIÓCESIS DE ÁVILA Y EL EPISCOPADO DE LA REPOBLACIÓN (1085-1198) 170 JOSÉ ANTONIO CALVO GÓMEZ

dificultades cierto Domingo, al que esta misma documentación sitúa en estas fechas, a consecuencia de un nuevo error diplomático, como prelado de la sede abulense ${ }^{66}$.

El 21 de junio de 1170, Alejandro III (1159-1181) exigió al abad y a los canónigos de San Isidoro de León que acudieran a la citación y acatasen la sentencia que dictaran los obispos de Astorga y Avila como jueces pontificios en el pleito que sostenían contra el obispo Pedro, de Salamanca, sobre la iglesia de Santa María de la Vega de esta ciudad ${ }^{67}$. El 12 de junio de 1181, el mismo pontífice comisionó a los obispos de Palencia, Ávila y Oviedo para que intervinieran, en su nombre, en el pleito que mantenía el obispo de León con el abad de Sahagún sobre ciertas parroquias de la villa ${ }^{68}$. Ángel Barrios, al respecto, transcribió varios documentos muy significativos ${ }^{69}$. Recuperamos dos. En 1176, Alfonso VIII (1158-1214) concedió a la Catedral de Ávila y a su obispo Sancho la tercera parte de las rentas reales en dicha ciudad. En 1179, como hemos citado arriba, Alejandro III (1159-1181) confirmó a este mismo prelado todas las posesiones que ya tenía y le concedió plena potestad sobre las iglesias de los términos de Ávila, Arévalo y Olmedo, y sobre los monasterios de Burgohondo y Gómez Román. La consolidación de la Iglesia abulense era ya una realidad.

Entre 1182 y 1187, rigió la sede abulense el obispo Domingo I. Así se desprende, entre otros lugares, de la documentación que se conserva en el Archivo de la Catedral de Ávila ${ }^{70}$. Los dos diplomas que hemos localizado en el Archivo Secreto Vaticano para estas fechas, sin embargo, plantean una nueva duda. El primero, fechado en 1184, habla de cierto Pedro en la sede abulense. Es cierto que deberíamos darle un valor muy

VIII (1158-1214) a la iglesia de Santa María de Huerta y al abad Martín. No dice nada más que «Sancius, abulensis episcopus, confirmat». Está datada en Huerta, el 20 de marzo de 1179 (tertiodecimo Kalendas aprilis era MCCXVII). Vid. ASV, Sale Sixto V. XLVI D3. Año 1179. Sanctius abulensis episcopus. Vid. MansI, Sacrorum conciliorum, t. II, p. 699, col. B. Ref. Schedario Garampi 31, Indice 475, Vescovi 1, fol. 49r, schede 11 e 12. Año 1179. Sancius abulensis episcopus. Vid. Achery, Jean Luc d'. Spicilegium sive collectio veterum aliquot scriptorum qui in Galliae bibliothecis delituerant. Nova editio. Parisis: Apud Montalant, 1723, t. I, p. 639. Ref. Schedario Garampi 31, Indice 475, Vescovi 1, fol. 49r, scheda 14.

${ }_{66}$ Año 1172. Dominicus (sic) abulensis episcopus. Vid. Muratori, Ludovico Antonio. Rerum Italicarum scriptores praecipui, ab anno aerae christ. D. ad MD. Mediolani: [s. n.], 1723, t. III, p. 390, col. C. Ref. Schedario Garampi 31, Indice 475, Vescovi 1, fol. 49r, scheda 10. Vid. ASV, Sale Sixto V. XLV A3. Se trata de ciertas crónicas de la historia de Italia y, por tanto, de fuentes secundarias sin ningún soporte documental.

67 1170. Abulensis. Vid. Domínguez SÁnchez, Documentos pontificios, pp. 98-99.

68 1181. Abulensis. Vid. Ibidem, pp. 118-119.

69 Barrios García, Documentación medieval de la catedral de Ávila, pp. 12-17. Vid. AHN, Sección Clero, Pergaminos, carp. 18, n. ${ }^{\circ}$ 4, de 30 de enero de 1176; AHN, Sección Clero, Pergaminos, carp. 18, n. ${ }^{\circ}$ 10, de 19 de julio de 1176; AC, doc. 6, de 21 de abril de 1179; AHN, Sección Clero, Pergaminos, carp. 18, n. ${ }^{11}$, de 14 de mayo de 1181; y AHN, Sección Clero, Pergaminos, carp. 18, n.o 12 , de 12 de noviembre de 1181, todos sobre el ministerio de Sancho II (1160-1181).

70 Ibídem, pp. 17-26. Vid. AHN, Sección Clero, Pergaminos, carp. 18, n. ${ }^{\circ} 13$, de 8 de julio de $1182-$ 1183; AC, doc. 7, de 13 de julio de 1182-1183; AHN, Sección Clero, Pergaminos, carp. 18, n.o 15, de 1183; AC, doc. 7, de 19 de febrero de 1184-1185; AHN, Sección Clero, Pergaminos, carp. 18, n. ${ }^{\circ} 16$, de 7 de junio de 1184-1185; AHN, Sección Clero, Pergaminos, carp. 18, n. ${ }^{\circ}$ 17, de 21 de octubre de 1185; AC, doc. 8, de 6 de mayo de 1186-1187; AHN, Sección Clero, Pergaminos, carp. 18, de 1 de enero de 1187. Vid. GonzÁLEZ, El reino de Castilla, p. 664 (doc. 382, de 12 de marzo de 1182) y p. 676 (doc. 390, de 3 de diciembre de 1190). Estos documentos se refieren al ministerio del obispo Domingo I Blasco (1182-1187) o Domingo Pérez. Vid. Cianca, fol. 81r; Ariz, fol. 37r; González Dávila, fol. 246; Tello, p. 149. 
limitado ya que se trata de una confirmación de ciertas donaciones de Alfonso VIII al monasterio de Huerta en la que podemos leer, sin más detalles: «Petrus, abulensis episcopus, confirmat» ${ }^{71}$. El segundo diploma vaticano no aclara el nombre del prelado, pues utiliza el genérico «abulensis» para referirse, con fecha del 20 de diciembre de 1184, a cierta comisión que el papa Lucio III (1181-1185) hizo en las personas de los obispos de Palencia y Ávila para que impidieran que el abad y los monjes de Sahagún, y los clérigos de la colegiata de Valladolid, usurparan la jurisdicción del obispo de León en algunos territorios e iglesias ${ }^{72}$.

A pesar de las dudas, por tanto, parece razonable sostener, con Ángel Barrios y Tomás Sobrino, las fechas y la nomenclatura de este quinto prelado abulense en la etapa de repoblación. Sobrino añade que asistimos, entonces, a una «larga etapa de consolidación de la estructura y funcionamiento canónico y pastoral de una diócesis que crecía con los años y las conquistas» ${ }^{73}$. En 1181, con la mediación de los obispos de Zamora y Salamanca, delegados del papa Lucio III (1181-1185) para dirimir este particular, se puso fin a ciertos pleitos que enfrentaban a los clérigos de la ciudad y a los de las aldeas de su término en el reparto de los diezmos del territorio. Se determinó que cada parte obtendría la mitad de este beneficio, salvados los intereses del prelado y del cabildo de la Catedral ${ }^{74}$.

El mismo pontífice exhortó a los caballeros y a los fieles de Ávila, Arévalo y Olmedo a que pagasen los diezmos en las iglesias en las que recibían los sacramentos, y no en aquellas de su elección ${ }^{75}$. Se empiezan a percibir algunas dificultades con los límites diocesanos con Segovia, para cuya resolución el papa Lucio III comisionó a los obispos de Sigüenza y Salamanca ${ }^{76}$; y, en otro sentido, también aparecieron algunas tensiones en el seno de la Iglesia abulense. El mismo pontífice remitió ciertas cuestiones a los arzobispos de Toledo y Santiago, así como a los obispos de Segovia y Sigüenza, para que resolvieran una lista de quejas que, de diversos lugares, habían llegado a la sede romana ${ }^{77}$.

Entre otras, el pontífice anotó que los laicos se sentían ultrajados, según explicó: «Adiecerunt etiam quod, cum olim populus civitatis fabrice ecclesie cathedralis excusatum, de singulis parrochiis ad tempus de gratia concessisset, episcopus violenter extorquere contendit, tanquam perpetuo fuisset deputatus operi supradicto». Es decir, que los laicos se quejaban porque el obispo quería perpetuar las ofrendas que, de forma extraordinaria,

71 1184. Petrus abulensis episcopus. Vid. ManriQue, Cisterciensium seu varius ecclesiasticorum annalium, p. 150. Ref. Schedario Garampi 31, Indice 475, Vescovi 1, fol. 49r, scheda 15. Esta confirmación está datada en Huerta, el 15 de marzo de 1184 (XVIII Kalendas aprilis era MCCXXII). Vid. ASV, Sale Sixto V. XLVI D3. González, El reino de Castilla, vol. 1, p. 514, señaló, de hecho, la falsedad de este documento, respaldando, por tanto, nuestra interpretación sobre la cronología del episcopado abulense entre 1181 y 1187 , cuando ocuparía la sede de san Segundo el obispo Domingo I.

72 1184. Abulensis. Vid. Domínguez Sánchez, Documentos pontificios, pp. 131-132.

73 Sobrino Chomón, «La Iglesia de Ávila. El territorio», p. 16.

74 Sobrino Chomón, Tomás. Documentación medieval del cabildo de San Benito de Ávila. Ávila: Institución Gran Duque de Alba, 1991, pp. 15-16 (doc. 1, de 17 de julio de 1183).

75 AHN, Sección Clero, Pergaminos, carp. 18, n. ${ }^{\circ} 13$. Vid. Barrios García, Documentación medieval de la catedral de Ávila, p. 17.

76 AC, doc. 7. Vid. Barrios García, Documentación medieval de la catedral de Ávila, p. 18.

77 AHN, Sección Clero, Pergaminos, Carp. 18, n. ${ }^{\circ}$ 16. Vid. Barrios García, Documentación medieval de la catedral de Ávila, pp. 21-23. 
LA RESTAURACIÓN DE LA DIÓCESIS DE ÁVILA Y EL EPISCOPADO DE LA REPOBLACIÓN (1085-1198) 172 JOSÉ ANTONIO CALVO GÓMEZ

se habían aprobado para la construcción de la catedral. Se conserva la sentencia de Lucio III (1181-1185) de 1185, confirmada, al año siguiente, por el papa Urbano III (1185-1187).

El penúltimo pontificado de este largo siglo de consolidación de la Iglesia abulense fue el de Domingo II (1187-1190) ${ }^{78}$, breve pero muy significativo a causa de un acontecimiento singular que, sin duda, debió de representar el primer revés en la reconstrucción medieval de la diócesis. Nos referimos a la segregación del arcedianato de Plasencia y Tierra de Segura, ratificado, de facto, en 1190. En 1187, Urbano III (1185-1187) había confirmado al obispo abulense la posesión de la comarca extremeña de Segura, al otro lado de la sierra, recién repoblada "que ad culturam noviter est redacta»" Tras el brevísimo pontificado de Gregorio VIII en 1187, Clemente III (1187-1191), con fecha del 28 de junio de 1188, ordenaba al arcediano, al clero y al pueblo placentino que se sometieran a la obediencia del obispo de Ávila ${ }^{80}$ y, con fecha del 1 de julio siguiente, confirmaba al mismo prelado los derechos sobre Segura y Plasencia ${ }^{81}$. El 7 de junio de 1190, el mismo pontífice tuvo que pedir a los obispos de Burgos y Oviedo que averiguasen la verdad sobre las acusaciones que el obispo Domingo II lanzaba contra el arcediano de Plasencia, que ya no se quería someter a su paternal jurisdicción ${ }^{82}$.

En 1190, se menciona ya a cierto Bricio como el primer obispo de la nueva diócesis de Plasencia ${ }^{83}$ a pesar de que, todavía en 1191, el arzobispo Pedro, de Santiago, se dirige al arcediano, al clero y al pueblo de este territorio para que respeten los derechos del obispo abulense ${ }^{84}$. A instancias de este mismo pueblo y clero placentinos, la actuación del rey Alfonso VIII, que había repoblado la ciudad en 1186, motivó la definitiva creación de la nueva sede episcopal, segregada del territorio abulense.

Elúltimo prelado de esta seriefue Juan I (1191-1195) que, según la documentación pontificia, murió en 1195 en la batalla de Alarcos ${ }^{85}$. Antes, refiere Barrios, había intercambiado

78 La documentación conservada en el ASV habla, en 1187, de "Gomes abulensis episcopus». Vid. Manrique, Cisterciensium seu varius ecclesiasticorum annalium, p. 201. Ref. Schedario Garampi 31, Indice 475, Vescovi 1, fol. 49v, scheda 2. Se trata de la confirmación de un documento de donación de Alfonso VIII de Castilla a la iglesia de Santa María la Real de Burgos y a su abadesa, Misol. No dice nada más que «Gomes, abulensis episcopus, conf.». Está datada en Burgos el 1 de junio de 1187 (era millesima centesima vigesimaquinta, Kalendis Iunii). Vid. ASV, Sale Sixto V. XLVI D3. Sin embargo, no existe duda diplomática sobre el ministerio de Domingo Velasco entre 1182 y 1187. En la historiografía de la Modernidad, se refieren a él Cianca, fol. 81r; Ariz, fol 37r; González Dávila, fol. 246; y Tello, p. 150.

79 AHN, Sección Clero, Pergaminos, carp. 18, n. ${ }^{\circ}$ 4. Vid. Barrios García, Documentación medieval de la catedral de Ávila, pp. 26-27 (doc. 30, de 6 de mayo de 1187). Sobre el mismo prelado, vid. GonZÁLEZ, El reino de Castila, p. 676 (doc. 390, de 3 de diciembre de 1190).

80 AHN, Sección Clero, Pergaminos, carp. 18, n. ${ }^{4}$. Vid. Barrios García, Documentación medieval de la catedral de Ávila, p. 27 (doc. 31).

${ }_{81}$ AHN, Sección Clero, Pergaminos, carp. 18, n. ${ }^{\circ}$ 4. Vid. Barrios García, Documentación medieval de la catedral de Ávila, p. 28 (doc. 32).

${ }^{82}$ AHN, Sección Clero, Pergaminos, carp. 18, n. ${ }^{\circ}$ 4. Vid. Barrios García, Documentación medieval de la catedral de Ávila, pp. 28-29 (doc. 34).

83 González Cuesta, Francisco. «Sobre el episcopologio de Plasencia». Hispania Sacra, 1995, vol. 47, pp. 347-376.

${ }_{84}$ AHN, Sección Clero, Pergaminos, carp. 18, n. ${ }^{4}$. Vid. Barrios García, Documentación medieval de la catedral de Ávila, pp. 29-30 (doc. 35).

85 1195. Abulensis episcopus ocesius. Vid. MANRIQUe, Cisterciensium seu varius ecclesiasticorum annalium, p. 290. Ref. Schedario Garampi 31, Indice 475, Vescovi 1, fol. 49v, scheda 1. Dice: «Era MCCXXXIII, 
ciertas propiedades del maestro Fruchel, ya desaparecido, con el rey Alfonso VIII ${ }^{86}$. Cuando todavía era arcediano de la Catedral, había suscrito un documento fundamental para validar el acuerdo sobre los diezmos con el obispo de Ávila y, en lo que a nosotros compete, para confirmar la sucesión de los prelados abulenses durante el siglo XII.

Según el regesto que Barrios hace del diploma, fechado en $1191^{87}$, se trata de un «acuerdo del Cabildo sobre el reparto de diversos derechos entre este y el obispo de Ávila, que contiene varias concesiones de los obispos abulenses del siglo xıI: Íñigo, Sancho, Domingo I y Domingo II». Entre otros derechos, les corresponde a los canónigos abulenses un tercio de los diezmos de Olmedo y la presentación al obispo de los clérigos que debían regir sus iglesias. La misma relación de los prelados, escrita en 1191, resulta ser una nueva confirmación de las afirmaciones prosopográficas que venimos haciendo.

Tras la muerte de Juan en la batalla de Alarcos, librada entre el 18 y el 19 de julio de 1195 cerca de Ciudad Real ${ }^{88}$, fue elegido Jacobo (1195-1203) que confirmó este acuerdo, en 1197, con estas palabras:

Después de la muerte del obispo Domingo segundo, de feliz memoria, el mencionado arcediano, Juan, elevado al episcopado, concedió validez a todos estos hechos; pero, la muerte, que le sobrevino en Alarcos, le impidió imponerles el sello. Pero yo, Jacobo, por la gracia de Dios instituido obispo de la Iglesia de Âvila después de esto, apruebo y confirmo y, en testimonio de verdad, corroboro esta presente carta con mi propio sello ${ }^{89}$.

\section{Conclusión}

En definitiva, durante el siglo XII, un territorio que, hacia 1085, yacía eclesialmente desmantelado, llegó a alcanzar, por la actuación combinada de los reyes de León y de Castilla, de los papas de Roma y de los ocho titulares de la sede de san Segundo, una estructura perfectamente organizada que, aunque se desarrollará ampliamente a lo largo de la Baja Edad Media, contó ya, a principios del siglo xıII, con una verdadera solidez institucional.

quarto Kalendas Augusti, lis magna fuit inter christianos et saracenos in loco qui dicitur Alarcos, praesenti Amiramolim ex parte saracenorum, et ex parte christianorum rege domino Alfonso Castellae, qui victus fugam petiit. In quo praelio interfecti fuerunt tres episcopi, videlicet, abulensis, segouiensis et seguntinus». Vid. ASV, Sale Sixto V. XLVI D3. También: 1195. Abulensis episcopus obiit. Vid. Flórez, España sagrada. p. 334. Ref. Schedario Garampi 31, Indice 475, Vescovi 1, fol. 49v, scheda 3.

${ }^{86}$ AHN, Sección Clero, Pergaminos, carp. 19, n. ${ }^{\circ}$ 4. Vid. Vid. Barrios García, Documentación medieval de la catedral de Ávila, p. 32 (doc. 37).

87 AHN, Sección Clero, Pergaminos, carp. 19, n. ${ }^{\circ}$ 1. Vid. Barrios García, Documentación medieval de la catedral de Ávila, pp. 30-32 (doc. 36).

88 Gonzálvez Ruiz, Ramón. Hombres y libros de Toledo. Madrid: Fundación Ramón Areces, 1997, p. 105, recoge una nota sobre su muerte que se ańade en el martirologio de Usardo.

89 Literalmente: «Defuncto quidem, felicis memorie, episcopo Dominico secundo, predictus archidiaconus Ioannes, in episcopatum sublimatus, totum factum istud concessit, sed morte preventus apud Alarchos sigillum non apposuit; sed ego, Iacobus, per Dei gratiam, abulensis Eclesie, postea institutus episcopus factum istud, approbo et confirmo et, in veritatis testimonium, presentem cartam proprii sigili munimine corroboro». AHN, Sección Clero, Pergaminos, carp. 19, n. ${ }^{2}$. Vid. Barrios García, Documentación medieval de la catedral de Ávila, pp. 37-38 (doc. 41). 
LA RESTAURACIÓN DE LA DIÓCESIS DE ÁVILA Y EL EPISCOPADO DE LA REPOBLACIÓN (1085-1198) 174 JOSÉ ANTONIO CALVO GÓMEZ

La obra de la catedral, en construcción, pudo acoger ya el cuerpo del obispo Jacobo, desparecido en 1203, que fue sepultado en el trasaltar de la seo. Esta fábrica se sumaba a la de numerosas parroquias urbanas y rurales que fueron repoblando el territorio, sobre todo al norte de la diócesis. La mayoría fueron servidas por los canónigos de la Catedral, como las del Valle Amblés; o por párrocos elegidos por los mismos feligreses, normalmente entre sus mismos congéneres. Se establecieron definitivamente los arcedianatos de Ávila, Arévalo y Olmedo, que recorrerán toda la Edad Media con notable vigor. El cabildo de la Catedral, que eligió durante siglos al obispo diocesano bajo la atenta mirada del metropolitano de Santiago, fue incrementando su personal con nuevas dignidades de acuerdo a las posibilidades que ofrecía una tierra en expansión.

Los límites con las diócesis de Salamanca y Palencia se dieron por cerrados a principios del siglo XIII. En pocos años, también se delimitará la jurisdicción de la mitra abulense en su frontera oriental, que la separaba con Segovia. Como podemos entender, a raíz de la segregación de Plasencia, en 1190, las dificultades con este nuevo obispado se adentraron, a lo largo del siglo XIII, todavía muchos años. Lo mismo sucedió con la frontera toledana, sobre todo después de la batalla de las Navas de Tolosa, en 1212. Estas disputas se mantuvieron activas hasta bien entrado el siglo XIII. En cualquier caso, la Iglesia de Ávila, que sucumbía a principios del siglo viı bajo el islam, recuperó su protagonismo en la historia a finales del siglo XI y, a lo largo de un intenso siglo XII, llegó a consolidar una presencia significativa.

\section{REFERENCIAS BIBLIOGRÁFICAS}

AcherY, Jean Luc d'. Spicilegium sive collectio veterum aliquot scriptorum qui in Galliae bibliothecis delituerant. Nova editio. Parisis: Apud Montalant, 1723, 3 vols.

Ariz, Luys. Historia de las grandezas de la ciudad de Ávila. Alcalá de Henares: Luys Martínez Grande, 1607.

Ayora, Gonzalo de. Epilogo de algunas cosas dignas de memoria pertenecientes a la yllustre e muy magnifica e muy leal ciudad de Ávila. Salamanca: Lorenzo de Liom de Dei, 1519 (Madrid: Antonio del Riego, 1851).

Barrios García, Ángel. «Conquista y repoblación: el proceso de reconstrucción del poblamiento y el aumento demográfico», y «Repoblación y colonización: la dinámica de creación de paisajes y el crecimiento económico». En Barrios García, Ángel (coord.). Historia de Ávila. Vol. II, Edad Media (siglos VIII-XIII). Ávila: Institución Gran Duque de Alba, 2000, pp. 227-270 y $271-336$.

Barrios García, Ángel. «Repoblación de la zona meridional del Duero. Fases de ocupación, procedencias y distribución espacial de los grupos repobladores». Studia Historica. Historia Medieval, 1985, vol. 3, pp. 33-82.

Barrios García, Ángel. «Romanización y reconquista en la Península Ibérica: nuevas perspectivas». Cassiodorus, 1997, vol. 3 pp. 147-152.

Barrios García, Ángel. Documentación medieval de la catedral de Ávila. Salamanca: Ediciones Universidad de Salamanca, 1981.

Barrios García, Ángel. Documentos de la catedral de Ávila (siglos XII-XIII). Ávila: Ediciones de la Institución Gran Duque de Alba, 2004. 
LA RESTAURACIÓN DE LA DIÓCESIS DE ÁVILA Y EL EPISCOPADO DE LA REPOBLACIÓN (1085-1198) JOSÉ ANTONIO CALVO GÓMEZ

Barrios García, Ángel. La catedral de Avila en la Edad Media. Estructura socio-jurídica y económica (hipótesis y problemas). Ávila: Obra Social y Cultural de la Caja Central de Ahorros y Préstamos de Ávila, 1973.

Barrios García, Ángel (ed.). Segunda Leyenda de la muy noble, leal y antigua ciudad de Ávila. Ávila: Institución Gran Duque de Alba, 2005.

Belmonte Díaz, José. La ciudad de Avila. Estudio histórico. 3.a ed. Ávila: Caja de Ahorros de Ávila, 1997.

Bullarum diplomatum et privilegiorum sanctorum romanorum pontificum. Taurinensis editio. Locupletior facta. Collectione novissima plurium brevium, epistolarum, decretorum actorumque $S$. Sedis a s. Leone Magno usque ad praesens. Vol. II, Ab Alexandro II (an. MLXI) ad Alexandrum III (an. MCLXXXI). Augustae Taurinorum: Sebastiano Franco et filiis editoribus, 1865.

Bullarum diplomatum et privilegiorum sanctorum romanorum pontificum. Taurinensis editio. Locupletior facta. Collectione novissima plurium brevium, epistolarum, decretorum actorumque $S$. Sedis a s. Leone Magno usque ad praesens. Vol. III, Ab Lucio III (an. MCLXXXI) ad Clementem IV (an. MCCLXVIII). Augustae Taurinorum: Sebastiano Franco et filiis editoribus, 1868.

Bullarum privilegiorum ac diplomatum Romanorum Pontificum amplissima collectio cui accessere pontificum omnium vitae, notae et indices opportuni. Vol. II, Ab Alexandro II ad Alexandrum III, scilicet ab an. MLXI ad MCLXXXI. Romae: Typis S. Michaelis ad Ripam, 1739.

Bullarum privilegiorum ac diplomatum Romanorum Pontificum amplissima collectio cui accessere pontificum omnium vitae, notae et indices opportuni. Vol. III, A Lucio III ad Clementem IV, scilicet ab an. MCLXXXI ad an. MCCLXVIII. Romae: Typis et sumptibus Hieronymi Mainardi, 1740.

Calvo Gómez, José Antonio. «Cuatro crónicas sobre el origen del monasterio de Santa María de Burgohondo (siglo xI)». Salmanticensis, 2009, vol. 56, pp. 315-356.

Calvo Gómez, José Antonio. "Rasgos de la reforma del clero en la Península Ibérica durante el siglo XI». Studia Historica. Historia Medieval, 2015, vol. 33, pp. 201-232.

Calvo Gómez, José Antonio. El monasterio de Santa María de Burgohondo en la Edad Media. Ávila: Institución Gran Duque de Alba, 2009.

Cantarella, Glauco Maria. Il sole e la luna. La rivoluzione di Gregorio VII, papa 1073-1085. Roma-Bari: Laterza, 2005.

Casa Martínez, Carlos de la. «Despoblación y repoblación de los Extrema Durii». En: Repoblación y reconquista. Actas del III Curso de cultura medieval. Aguilar de Campoo: Centro de Estudios del Románico, 1993, pp. 89-94.

Cianca, Antonio de. Historia de la vida, invención, milagros y translación de S. Segundo, primero Obispo de Auila: y recopilación de los Obispos sucessores suyos, hasta D. Geronimo Manrique de Lara, inquisidor general de España. Madrid: por Luis Sánchez, 1595.

Colmenares, Diego. Historia de la insigne ciudad de Segovia y compendio de las historias de Castilla. Segovia: Eduardo Baeza, 1869, 3 vols.

David, Pierre. Études historiques sur la Galice et le Portugal: du VIe au XII siècle. Lisboa: Livraria Portugália, 1947.

Deswarte, Tomas. Une Chrétienté romaine sans pape: l'Espagne et Rome (586-1085). Paris: Garnier, 2010.

Domínguez SÁnchez, Santiago. Documentos pontificios referentes a la diócesis de León (siglos XIXIII). León: Universidad de León, 2003.

Engel, Frank y Martín Martín, José Luis (eds.). Iberia Pontificia sive repertorium privilegiorum et litterarum a romanis pontificibus ante annum MCLXXXXVIII Hispaniae et Portugalliae ecclesiis, monasteriis, civitatibus singulisque personis concessorum. Vol. IV, Provincia Compostellana. Dioeceses Abulensis, Salmanticensis, Cauriensis, Civitatensis, Placentina. Göttingen: Vandenhoeck \& Ruprecht, 2016. 
LA RESTAURACIÓN DE LA DIÓCESIS DE ÁVILA Y EL EPISCOPADO DE LA REPOBLACIÓN (1085-1198) 176 JOSÉ ANTONIO CALVO GÓMEZ

Estepa Díez, Carlos. El reinado de Alfonso VI. Madrid: Spainfo, 1985.

Eubel, Conradum. Hierarchia catholica Medii Aevi sive summorum pontificum, sacra romana Ecclesia cardinalium ecclesiarum antistitum series ab anno 1198 usque ad annum 1431 perducta e documentis tabularii praesertim Vaticani collecta, digesta, edita. 2. ${ }^{a}$ ed. Patavii: Il Messaggero di S. Antonio, 1923.

Fernández Valencia, Bartolomé. Historia y grandezas del insigne templo... de los santos mártires hermanos San Vicente, Santa Sabina y Santa Cristeta... con un comentario o epilogo de las grandezas de esta ciudad, 1676, ed. de Tomás Sobrino Chomón. Ávila: Institución Gran Duque de Alba, 1992.

Flórez, Enrique. España Sagrada. Theatro geográphico histórico de la Iglesia de España. Origen, divisiones y limites de todas sus provincias, antigüedad y traslaciones, y estado antiguo y presente de sus sillas, con varias disertaciones críticas. Tomo XIV. De las Iglesias de Ábila, Caliabria, Coria, Coimbra, Ébora, Egitania, Lamego, Lisboa, Osonoba, Pacense, Salamanca, Viseo y Zamora, según su estado antiguo. Madrid: Imprenta de Pedro Martín, 1786.

Gamba, Andrés. Alfonso VI. Cancillería, curia e imperio. León: Centro de Estudios e Investigación San Isidoro, 1997-1998, 2 vols.

Gams, Pius Bonifacius. Series episcoporum Ecclesiae catholicae quot quot innotuerunt a beato Petro apostolo. Ratisbonae: Typis et sumtibus Georgii Josephi Manz, 1873.

González Cuesta, Francisco. «Sobre el episcopologio de Plasencia». Hispania Sacra, 1995, vol. 47, pp. 347-376.

González Dávila, Gil. Teatro eclesiástico de la S. Iglesia Apostólica de Ávila y vidas de sus hombres ilustres. Madrid: en la imprenta de Pedro de Horna y Villanueva, 1647.

González, Julio. «La Extremadura castellana al mediar el siglo XIII». Hispania, 1974, vol. 127, pp. 265-424.

GonZÁLEZ, Julio. «La repoblación de la Extremadura leonesa». Hispania, 1943, vol. 11, pp. 195273.

González, Julio. El reino de Castilla en la época de Alfonso VIII. Madrid: Escuela de Estudios Medievales, 1960, 3 vols.

Gonzálvez Ruiz, Ramón. Hombres y libros de Toledo. Madrid: Fundación Ramón Areces, 1997.

Historia Compostelana. España Sagrada, tomo XX. Madrid: Imprenta de Pedro Martín, 1765.

Jiménez de Rada, Rodrigo. Historia de los hechos de España, ed. de Juan Fernández Valverde. Madrid: Alianza: 1989.

Jiménez Duque, Baldomero. Ávila mística. Ávila: Ediciones de la Obra Cultural de la Caja de Ahorros de Ávila, 1992.

Lacombe, Claude. Jerónimo de Perigueux (¿1060?-1120). Obispo de Valencia y de Salamanca. Un monje caballero en la reconquista. Salamanca: Universidad Pontificia de Salamanca, 2000.

Magaz Fernández, José María y Álvarez de las Asturias, Nicolás (eds.). Reforma Gregoriana en España. Madrid: Universidad San Dámaso, 2011.

MANRIQue, Ángel. Cisterciensium seu verius ecclesiasticorum annalium a condito Cistercio. Lugduni: Sumpt. Haered. G. Boissat \& Laurent Anisson, 1642-1659, 4 vols.

Mansi, Joannes Dominicus. Sacrorum Conciliorum nova et amplissima collectio. Florentiae Venetiis: Antonius Zatta, 1778.

Martín Carramolino, Juan. Historia de Ávila, su provincia y obispado. Ávila: Librería Española, 1872-1873, 3 vols.

Martín Viso, Ińaki. «Capere vel populare. Formación y desarrollo de una frontera feudal entre el Duero y el Tajo (siglos XI-XIII)». En Balaguer 1105. Cruilla de civilitzacions. Lleida: Pagès Editors, 2007, pp. 177-223. 
LA RESTAURACión DE LA DiÓCESIS DE ÁVILA Y EL EPISCOPADO DE LA REPOBLACIÓN (1085-1198) JOSÉ ANTONIO CALVO GÓMEZ

Martínez, Gonzalo. «Restauración y límites de la diócesis palentina». Publicaciones de la Institución Tello Téllez de Meneses, 1988, vol. 59, pp. 351-386.

Mazel, Florian. «Cuius dominus, eius episcopatus? Pouvoir seigneurial et territoire diocésain ( $\mathrm{x}^{\mathrm{e}}$ XIII ${ }^{\mathrm{e}}$ siècle)». En Mazel, Florian (ed.). L'espace du diocèse. Genèse d'un territoire dans l'Occident médiéval (V'-XII ${ }^{e}$ siècle). Rennes: Presses Universitaires de Rennes, 2008, pp. 213-252.

Menéndez Pidal, Ramón (ed.). Primera crónica general. Estoria de España que mandó componer Alfonso el Sabio y se continuaba bajo Sancho IV en 1298. Madrid: Bailly Baillière e Hijos, 1906

MenÉndez Pidal, Ramón. «Repoblación y tradición en la cuenca del Duero». En Enciclopedia lingüistica hispánica. Madrid: Consejo Superior de Investigaciones Científicas, 1960, vol. I, pp. 29-57.

Menéndez Pidal, Ramón. La España del Cid. 7. a ed. Madrid: Espasa-Calpe, 1967.

Minguella y Arnedo, Toribio. Historia de la diócesis de Sigüenza y de sus obispos. Madrid: Imprenta de la Revista de Archivos, Bibliotecas y Museos, 1910, 3 vols.

Mínguez Fernández, José María. Alfonso VI: poder, expansión y reorganización interior. Hondarribia: Nerea, 2000.

Mínguez Fernández, José María y Ser Quijano, Gregorio del (coords.). La Peninsula en la Edad Media: treinta años después. Estudios dedicados a José-Luis Martín. Salamanca: Universidad de Salamanca, 2006.

Monsalvo Antón, José María. «El imaginario de la repoblación de Ávila: la Crónica de la Población, el Epílogo y la Segunda Leyenda». Anuario de Estudios Medievales, 2017, vol. 47, n. ${ }^{\circ}$ 1, pp. 177-210.

Montaner Frutos, Alberto. http//:caminodelcid.org.

Moxó Ortiz de Villajos, Salvador de. Repoblación y sociedad en la España cristiana medieval. Madrid: Rialp, 1979.

Muratori, Ludovico Antonio. Rerum Italicarum scriptores praecipui, ab anno aerae christ. D. ad MD. Mediolani: [s. n.], 1723.

PAstor, Reyna. «Claudio Sánchez-Albornoz, historiador, maestro y militante». En Pastor, Reyna (dir.). Sánchez-Albornoz a debate. Homenaje en la Universidad de Valladolid con motivo de su centenario. Valladolid: Universidad de Valladolid, 1993.

Quadrado, José María. Salamanca, Avila y Segovia. Barcelona: Daniel Cortezo y Compañía, 1884.

Rivera Recio, Juan Francisco. El arzobispo de Toledo don Bernardo de Cluny. Roma: Instituto Español de Historia Eclesiástica, 1962.

Rodríguez Almeida, Emilio. El cáliz de san Segundo. Ávila: Institución Gran Duque de Alba, 1997.

Rodríguez Morales, Jesús y González Agudo, David. «Los caminos de la repoblación segoviana en la Transierra entre los siglos XIII y Xv. El privilegio de las Alberguerías de 1273». Espacio, Tiempo y Forma. Serie III, Historia Medieval, 2019, vol. 23, pp. 303-336.

SÁnchez-Albornoz, Claudio. Despoblación y repoblación del valle del Duero. Buenos Aires: Instituto de Historia de España, 1966.

SÁnchez-Albornoz, Claudio. España, un enigma histórico. Buenos Aires: Editorial Sudamericana, 1956.

Serrano, Luciano. Cartulario de San Millán de la Cogolla. Madrid: Centro de Estudios Históricos, 1934

Serrano, Luciano. Cartulario de San Pedro de Arlanza. Madrid: Centro de Estudios Históricos, 1925. 
LA RESTAURACIÓN DE LA DIÓCESIS DE ÁVILA Y EL EPISCOPADO DE LA REPOBLACIÓN (1085-1198) 178 JOSÉ ANTONIO CALVO GÓMEZ

Sobrino Chomón, Tomás. «La Iglesia de Ávila. El territorio, los orígenes discutidos y la época medieval». En Egido López, Teófanes (ed.). Historia de las diócesis españolas. Vol. 18, Iglesias de Avila, Salamanca y Ciudad Rodrigo. Madrid: Biblioteca de Autores Cristianos, 2005, pp. 5-60.

Sobrino Chomón, Tomás. Documentación medieval del cabildo de San Benito de Ávila. Ávila: Institución Gran Duque de Alba, 1991.

Tello Martínez, José. Cathálogo sagrado de los obispos de Ávila (1788), ed. de Félix A. Ferrer García. Ávila: Institución Gran Duque de Alba, 2001.

Ubieto Arteta, Antonio. Listas episcopales medievales. 2 vols. Zaragoza: Anubar Ediciones, 1989. 